\title{
Validity of flowmeter data in heterogeneous alluvial aquifers
}

Marco Bianchi ${ }^{1}$

${ }^{1}$ British Geological Survey, Environmental Science Centre, Keyworth, Nottingham,

NG12 5GG, United Kingdom. marcob@bgs.ac.uk. Tel. +44 (0)155 9363136 


\section{Abstract}

2 Numerical simulations are performed to evaluate the impact of medium-scale sedimentary

3 architecture and small-scale heterogeneity on the validity of the borehole flowmeter test, a

4 widely used method for measuring hydraulic conductivity $(K)$ at the scale required for

5 detailed groundwater flow and solute transport simulations. Reference data from synthetic

$6 \quad K$ fields representing the range of structures and small-scale heterogeneity typically

7 observed in alluvial systems are compared with estimated values from numerical

8 simulations of flowmeter tests. Systematic errors inherent in the flowmeter $K$ estimates are

9 significant when the reference $K$ field structure deviates from the hypothetical perfectly

10 stratified conceptual model at the basis of the interpretation method of flowmeter tests.

11 Because of these errors, the true variability of the $K$ field is underestimated and the

12 distributions of the reference $K$ data and log-transformed spatial increments are also

13 misconstrued. The presented numerical analysis shows that the validity of flowmeter

14 based $K$ data depends on measureable parameters defining the architecture of the

15 hydrofacies, the conductivity contrasts between the hydrofacies and the sub-facies-scale $K$ 16 variability. A preliminary geological characterization is therefore essential for evaluating

17 the optimal approach for accurate $K$ field characterization.

\section{Keywords}

21 Hydraulic conductivity; Numerical simulation; Characterization methods; Hydrofacies;

22 Borehole flowmeter test 
Groundwater flow and solute transport are heavily influenced by the spatial

27 distribution of hydraulic conductivity $(K)$ in the subsurface. Therefore, an accurate

28 characterization of small-scale $\left(<10^{0} \mathrm{~m}\right) \mathrm{K}$ variations is essential for numerical simulations

29 at the typical scale of contaminated land remediation projects, which is in the order of few

30 hundreds of meters. Among the available methods for measuring $K$ at such fine scale in

31 porous aquifers, the borehole flowmeter test is one of the most commonly applied (e.g.,

32 Maliva, 2016). It was also the preferred technique for the characterization of the $K$ field at

33 a number of hydrogeological research sites (Hess, 1989; Molz et al., 1989; Rehfeldt et al.,

34 1992; Young, 1995; Vereecken et al., 2000; Riva et al. 2006; Li et al., 2008), and

35 extensive flowmeter based $K$ datasets have been used in myriad published studies in the

36 fields of geostatistics, stochastic subsurface hydrology, and groundwater flow and solute

37 transport modelling.

38 The borehole flowmeter test consists of measuring variations of vertical flow in a

39 fully penetrating well and subsequently relating these variations to the vertical distribution

40 of $K$ along the well. The test is usually performed by pumping groundwater at a constant

41 rate $Q_{w}$. After pseudo-steady state conditions are attained, a type of flowmeter

42 (Hufschmied, 1986; Molz. et al., 1989; Rehfeldt et al., 1989; Young, 1995; Young and

43 Pearson, 1995; Boman et al., 1997; Crisman et al., 2001; Newhouse et al., 2005) is

44 lowered in the well and flow measurements are taken at regularly spaced intervals starting

45 from near the bottom of the well (flow $\approx 0$ ) to the top (flow $\approx Q_{w}$ ).

46 The key assumption for the interpretation of flowmeter data is the conceptualization

47 of the aquifer as a perfectly stratified system (Javandel and Witherspoon, 1969). In these conditions, which in field applications are assumed to be obtained after a period of time 
49 from the beginning of pumping (i.e., pseudo-steady state conditions attained), flow in the

50 layers is horizontal and proportional to the hydraulic conductivity of the layer. By

51 assuming a perfectly stratified aquifer with layers of thickness $\Delta z_{i}$ equal to the spacing

52 between flowmeter readings, the hydraulic conductivity $K_{i}$ of a layer $i$ can then be

53 calculated according to (Molz et al., 1989):

$54 \quad K_{i}=\frac{\Delta Q_{i} Z}{Q_{w} \Delta z_{i}} \bar{K}$

55 where $\Delta Q_{i}$ is the discharge from layer $i$ into the well $\left(Q_{w}=\sum_{i} \Delta Q_{i}\right), Z$ is the aquifer

56 thickness (i.e., $Z=\sum_{i} \Delta z_{i}$ ), and $\bar{K}$ is an effective hydraulic conductivity value (e.g.,

57 Sanchez-Vila et al., 2006), which can be obtained from a previously performed pumping

58 test (e.g., Molz et al., 1989; Barahona-Palomo et al., 2011; Gueting et al., 2015). An

59 alternative interpretation approach of flowmeter data is the one proposed by Rehfeldt et al.

60 (1989), which was used for the characterization of the $K$ field at the Macrodispersion

61 Experiment (MADE) site (Rehfeldt et al., 1992; Zheng et al., 2011). This approach applies

62 an approximate solution (Cooper and Jacob, 1946) for calculating the drawdown $s_{i}$ in each

63 layer of an assumed perfectly stratified aquifer. Comparisons of $K$ profiles calculated from

64 flowmeter data using the approach represented by Equation 1 and the approach proposed

65 by Rehfeldt et al. (1989) show a fairly good agreement in a relatively homogenous aquifer

66 (Molz et al., 1989). Vertical distribution of $K$ values based on flowmeter tests and other

67 characterization methods have been compared in several previous studies (e.g., Molz et al.

68 1989; Boman et al. 1997; Whittaker and Teutsch, 1999; Zlotnik and Zurbuchen, 2003b;

69 Butler, 2005; Tilmann et al., 2008; Illman et al. 2010; Barahona-Palomo, 2011; Bohling et

70 al., 2012; Gueting et al., 2015; Bianchi and Zheng, 2016). 
Irrespective of the approach used for interpretation, flowmeter $K$ estimates are prone

72 to errors from different sources. For instance, the presence of a skin region or gravel pack

73 around the well induces vertical flow components producing biased measurements of $\Delta Q_{i}$

74 (Rehfeldt et al., 1989; Young, 1995; Boman et al., 1997). These components can

75 negatively impact the accuracy of the $K$ estimates especially in the presence of a skin

76 region (Xiang, 1995; Ruud and Kabala, 1997; Riva et al., 2012). If ignored, hydraulic

77 head losses can also generate errors in the $K$ estimates (e.g., Rehfeldt et al., 1989) caused

78 by unaccounted for vertical flow components (Boman et al., 1997; Dinwiddie et al., 1999;

79 Ruud et al., 1999; Zlotnik and Zurbuchen, 2003a). It was estimated that the combined

80 effect of hydraulic head losses and skin effects can lead to estimation errors of a factor 10

81 or higher (Ruud et al., 1999). Studies have evaluated the impact of variations of the

82 borehole diameter on flowmeter $K$ estimates (Paillet, 2004), and tested the validity of the

83 Theis (1935) model to represent the flow dynamics in the aquifer. A this regard, it was

84 shown numerically that the assumption of the Theis model produces systematic errors up

85 to factor of about 1.5 (Ruud and Kabala, 1996). Additional sources of random and

86 systematic errors are discussed in detail by Rehfeld et al. (1989).

87 To the best of our knowledge, no previous study has been conducted to evaluate

88 systematic errors in flowmeter data when the assumed model of a perfectly stratified

89 system is not representative of the actual aquifer structure. In alluvial aquifers, for

90 instance, variations of the textural properties of the sediments and consequentially of $K$

91 can occur over short lengths, not only in the vertical direction (in the order of $10^{-2}-10^{-1}$

92 meters), but also in the horizontal direction (in the order of $10^{0}-10^{1}$ meters) (e.g.,

93 Scheibe and and Freyberg 1995, Fogg et al., 1998; Heinz et al., 2003; Ramanathan et al.,

94 2010; Bayer et al., 2011; Dell'Arciprete et al., 2012; Bianchi and Zheng, 2016). A 
rigorous assessment of these systematic errors is also needed because datasets of

96 flowmeter $K$ estimates from multiple wells are often considered as conditioning points in

97 geostatistical analysis to generate three-dimensional representations of the $K$ field (e.g.,

98 Rehfeldt et al., 1992; Salomon et al., 2007, Li et al., 2008; Bianchi et al., 2011). The

99 reliability of these representations, which most often contradict the assumption of a

100 perfectly stratified system, depends on the representativeness of the conditioning data.

101 Building on previous analyses of other factors affecting the validity of the flowmeter

102 test, the main objective of this paper is to evaluate the effect of medium-scale sedimentary

103 architecture and small-scale variability on the accuracy of the $K$ estimates. As in the work

104 of Zhang et al. (2013), a transition probability based Markov chain model is used here to

105 represent the spatial distribution of hydrofacies in a generic alluvial aquifer, and several

106 scenarios representing a wide range of realistic geological conditions are considered in

107 numerical simulations of flowmeter tests. Simulated tests are then validated by comparing

108 resulting $K$ estimates with the "true" $K$ values of the hydrofacies. According to the

109 assumed conceptual model of aquifer heterogeneity, the structure of the reference $K$ field

110 is defined by the architecture of the hydrofacies, while the univariate statistical

111 distribution of $K$ is controlled by their volumetric proportions as well as by the smaller

112 scale variability within each hydrofacies. A similar geologically consistent

113 conceptualization of the $K$ field has been applied in several previous studies showing the

114 strong influence of the sedimentological architecture on groundwater flow and solute

115 transport (e.g., Anderson, 1989; Webb and Anderson, 1996; Fogg, 1986; Allen-King,

116 1998; Fogg et al., 1998, 2000; Weissman and Fogg, 1999; Weismann et al., 1999; Lu et

117 al., 2002; Lee et al., 2007; Riva et al., 2008; Bianchi and Zheng, 2016).

118 This work is also motivated by the absence of a clear explanation for the generally

119 poor correspondence between $K$ estimates from flowmeter tests and from grain-size 
121 Teutsch, 1999; Barahona-Palomo et al., 2011; Gueting et al., 2015; Bianchi and Zheng,

122 2016). Barahona-Palomo et al. (2011), for instance, compared these two types of $K$ data at

123 coinciding locations in an alluvial aquifer and found different values for the sample

124 variances and correlation lengths for the two datasets. These discrepancies have been

125 previously related to differences in support volume between the two types of

126 measurements. However, while the support volume of estimates based on the grain-size

127 approach can be precisely associated with the dimensions of the aquifer samples, the

128 support volume of flowmeter based $K$ estimates is not clearly defined (Zlotnick and

129 Zurbuchen, 2003b). The poor correspondence between these two types of estimates might

130 also be caused by systematic errors in the grain-size based values due to the empirical

131 nature of the relationship between a not precisely defined effective grain diameter and $K$.

132 However, modelling studies by Riva et al. (2008) and Bianchi and Zheng (2016) have

133 shown that grain-size based $K$ estimates are able to provide adequate information to

134 effectively simulate transport behaviour in heterogeneous medium- to coarse-grained

135 alluvial aquifers. The results of these studies can be considered as an indirect validation of

136 this approach for $K$ estimation. On the other hand, representations of the $K$ field based on

137 flowmeter $K$ data do not always explain observed tracer plumes (e.g., Feehley et al., 2000;

138 Salamon et al, 2007; Fiori et al., 2013).

1402 Methods

1412.1 Simulated scenarios of facies architecture

142 Hydrofacies architecture in a generic alluvial aquifer is simulated with the transition

143 probability geostatistical approach (T-PROGS; Carle and Fogg, 1996, 1997; Carle, 1999).

144 With this approach, the spatial structure of a categorical variable - here indicating 
145 different hydrofacies - is modelled with a Markov Chain model based on transition

146 probabilities between the categories at discrete lag distances. Markov chain models can be

147 implemented by knowing the entries in the embedded transition probability matrix, which

148 represents the conditional probabilities of one category to occur adjacent to the others

149 along a particular direction. The choice of a background category is also required to

150 eliminate the need to specify corresponding entries in the embedded transition matrix

151 since these are calculated by difference from the entries of the other categories.

152 Implemented Markov chain models are used by a geostatistical simulation algorithm to

153 generate stochastic realizations of the spatial distribution of the categories in either

154 conditional or unconditional frameworks. In these realizations, the background category

155 fills the space not occupied by the other categories.

156 The transition probability approach allows the generation of realistic representations

157 of the hydrofacies architecture on the basis of a combination of measurable and interpreted

158 geological properties including (1) the number of hydrofacies, (2) their volumetric

159 proportions, (3) their mean lengths along specific directions, (4) the anisotropy ratios

160 between mean lengths, and (5) the juxtapositional tendency. The latter defines the

161 predisposition for each hydrofacies to occur adjacent to others like, for instance, when

162 there are trends in the textural properties of the sediments along particular directions (e.g.,

163 fining upward sequences). In this work, a range of values are assigned to some of these

164 properties to generate several realistic scenarios of aquifer heterogeneity in which to

165 evaluate the validity of simulated flowmeter tests. However, to better fit the purpose of

166 this study, other properties including the number of lithofacies, their volumetric

167 proportions, and the juxtapositional tendency are kept constant in all the scenarios. The

168 motivation of this choice will become clear after the description of the reference $K$ fields. 
170 encountered in alluvial depositional systems, including a coarser and generally more

171 conductive hydrofacies representing, for example, fluvial channel deposits (hydrofacies

172 "H" or High), a finer and less conductive hydrofacies representing floodplain deposits

173 (hydrofacies "L" or "Low"), and a third hydrofacies with intermediate properties, which is

174 meant to represents deposits of other depositional elements such as levees and crevasse

175 splays (hydrofacies "I" or "Intermediate"). It is assumed that hydrofacies "L", which is

176 also considered as the background property in the Markov chain models, has the highest

177 volumetric proportion (0.5), while hydrofacies "I" and "H" have proportions equal to 0.2

178 and 0.3 , respectively. In the development of the Markov chain models, juxtapositional

179 tendencies are defined by the values in the embedded transition probability matrix in each

180 direction (Carle and Fogg, 1988; Carle, 1999). In all the scenarios, assigned embedded

181 probabilities were chosen to favour a vertical arrangement of the hydrofacies in fining-

182 upward successions, which are typical of fluvial deposits (Miall, 2014). Vertical

183 embedded probabilities were also assigned to embedded probabilities in the horizontal

184 directions ( $x$ and $y$ ), in accordance to Walther's Law (Fogg et al., 2000).

185 For each developed Markov chain model, one realization of the spatial distribution of

186 the hydrofacies is assumed as representative of the architecture for each scenario. These

187 realizations consider a rectangular domain of dimensions equal to 241 units $\left(u_{h}=0.5 \mathrm{~m}\right)$ in

188 the $x$ and $y$ directions, and 80 units $\left(u_{v}=0.5 u_{h}\right)$ in the vertical $(z)$ direction. Each cell of

189 the 3-D grid used for geostatistical simulation has a volume of $1 u_{h} \times 1 u_{h} \times 1 u_{v}$ for a total

190 of more than $4.6 \times 10^{6}$ cells.

191 Different scenarios are grouped on the basis of variations of a particular property

192 (Table 1). The first group (scenarios L_1 through L_inf) is represented by eight scenarios 
characterized by different isotropic horizontal mean lengths of the hydrofacies (

$194 L_{h}=L_{x}=L_{y}$ ). For simplicity, the same $L_{h}$ is assigned to hydrofacies "I" and " $\mathrm{H}$ ", while

195 the mean length of the background hydrofacies "L" varies in each scenario as a function of

$196 L_{h}$ and the embedded transition probabilities of the other hydrofacies (see Carle and Fogg,

1971997 for details). For the scenarios considered in this study, the horizontal mean length of

198 the background hydrofacies is about twice the mean length of the other hydrofacies. A

199 scenario representing a perfectly stratified architecture $\left(L_{h}=\infty\right)$ is also included in this

200 group. In this work, scenarios considering a perfectly stratified system represent

201 benchmark problems to test the validity of the numerical simulations. After the first

202 unconditional realization of hydrofacies architecture was generated considering $L_{h}=1 u_{h}$

203 (scenario L_1), the resulting vertical distribution of hydrofacies at the centre of the

204 domain was used as conditioning data in the remaining simulations such that the vertical

205 succession of hydrofacies at this location - which corresponds to the location of the

206 simulated flowmeter tests - is shared by all the scenarios.

207 The second group of scenarios (scenarios AR_1 through AR_16) was designed to test

208 the impact of the anisotropy ratio between the horizontal mean lengths of the lithofacies.

209 Different hydrofacies architectures were generated from modifications of an isotropic

210 Markov chain model with $L_{h}=4 u_{h}$. For each modification, the mean length in the $y$

211 direction $\left(L_{y}\right)$ is progressively augmented while the values of $L_{x}$ and $L_{z}$ remain constant.

212 Similarly to the previous group of scenarios, the vertical succession at the centre of the

213 domain is shared by all the scenarios.

214 The remaining groups in Table 1 allow the analysis of the effects of variations in $K$

215 between hydrofacies (scenarios L4_K1 through L16_K4), as well as within the

216 hydrofacies (scenarios L2_ede00 through Linf_ede80). The first of these groups considers 
217 scenarios with similar architecture, but different $K$ contrasts between hydrofacies " $H$ " and

218 "L". The effect of different architectures is also investigated, corresponding to different

219 isotropic horizontal mean lengths $\left(L_{h}=4 u_{h}\right.$ and $\left.L_{h}=16 u_{h}\right)$. For each $L_{h}$ value, four

220 different $K$ ratios are considered with values ranging from $10^{0}$ to $10^{4}$. Different levels of

221 intrafacies $K$ variability, which are evaluated in the last group of scenarios, are also

222 considered for different architectures (i.e., $L_{h}$ equal to $2 u_{h}$ and infinity). The approach for

223 simulating this small-scale variability is described in the following section.

\subsection{Reference hydraulic conductivity fields}

The link between simulated hydrofacies architectures and corresponding $K$ fields is established through the relationship between hydraulic conductivity and an effective grain-size diameter $d_{e}$. In a general form, this relationship can be written as (e.g., Vuković and Soro 1992):

230

$K=C \frac{g}{v} f(\phi) d_{e}^{2}$

231 where $g$ is the gravitational constant, $v$ is the kinematic viscosity, $f(\phi)$ is a function of the porosity, and $C$ is proportionality constant expressed in consistent units. With this approach, characteristic $d_{e}$ values were initially assigned to the hydrofacies and reference

$234 K$ values were then mapped on the basis of the simulated architectures. For the calculation

235 of the characteristic $K$ values of the hydrofacies, the largest and the lowest $d_{e}$ values are 236 assigned to hydrofacies " $H$ " and to hydrofacies "L", respectively. A similar porosity value 237 is assumed for all the hydrofacies (i.e., $f(\phi)=$ constant)

238 In previous studies, non-uniform $K$ distributions within the hydrofacies have been 239 simulated by combining stochastic facies and fractal models (Lu et al., 2002; Zhang et al., 240 2013), or by imposing log-normal $K$ distributions (Frei al., 2009). Both of these 
241 approaches make assumptions on the $K$ distribution within the hydrofacies. In this work,

242 small-scale variability is simulated with a different approach based on modelling the non-

243 uniform distribution of the effective diameter $d_{e}$ within the hydrofacies. For each

244 hydrofacies, the $d_{e}$ distribution is modelled with a spatially correlated Gaussian field, with

245 mean equal to $\bar{d}_{e}$ and standard deviation $\sigma$ defined as:

$246 \quad \sigma=\frac{\varepsilon_{d e} \overline{d_{e}}}{3}$

247 Spatial distributions of $d_{e}$ for each hydrofacies were generated with a sequential Gaussian

248 simulation code (Deutsch and Journel, 1998) by assuming an anisotropic exponential

249 variogram model with ranges equal to $2 u_{h}, 2 u_{h}$ and $1 u_{v}$ in the $x, y$ and $z$ directions,

250 respectively. Different levels of intrafacies variability are generated by varying the value

251 assigned to the parameter $\varepsilon_{d e}$, which controls the spreading of the Gaussian distribution of

$252 d_{e}$ within each hydrofacies. When, for example, $\varepsilon_{d e}=0.2$, the $99.7 \%$ of the $d_{e}$ values is

253 within a $20 \%$ range from the characteristic mean $\bar{d}_{e}$. For simplicity, the same $\varepsilon_{d e}$ values

254 are assigned to all the hydrofacies. These values were chosen to avoid superimpositions in

255 the resulting $K$ values of the different hydrofacies. As a result, the structure inherited from

256 the hydrofacies architecture is preserved in the $K$ fields, and the impact of intrafacies

257 variability on the global $K$ field variance is generally small (Table 1).

258 A fundamental feature of the synthetic $K$ fields used in this study is that for a given

$259 K_{H} / K_{L}$ ratio and a given $\varepsilon_{d e}$ value, the statistical distribution of the reference $K$ values is

260 shared by all the scenarios notwithstanding different structures. This is the result of the

261 choice of considering the same volumetric fractions for the hydrofacies in all scenarios. In

262 this regard, the present study is similar in spirit with previous analyses in which $K$ fields

263 with identical histogram, but with different spatial structures, have been compared to 
understand their impact on groundwater flow and solute transport (e.g., Wen and Gomez-

265 Hernandez, 1998; Western et al., 2001; Zinn and Harvey, 2003; Lee et al., 2007; Siirila-

266 Woodburn and Maxwell, 2015).

\subsection{Flowmeter test simulations}

Flowmeter tests are simulated with a three-dimensional finite-difference code (MODFLOW-2005, Harbaugh, 2005) considering steady-state convergent flow toward a

271 fully penetrating well in a confined aquifer. Hydraulic head $(h)$ and specific discharge $(q)$ 272 satisfy the following equations:

$273 \quad \mathbf{q}=-K \nabla h \quad \nabla \cdot \mathbf{q}+f=0$

274 where $K(x, y, z)$ is the reference $K$ field and $f$ is a volumetric term per unit volume of

275 aquifer representing fluid sources (positive) or withdrawals (negative). The numerical grid 276 is defined over a cylindrical domain of radius $120.5 u_{h}$, and the location of the well for 277 flowmeter test simulations is at the centre of the domain (Figure 1). A sensitivity analysis

278 was conducted to evaluate the precision of the model outputs with respect to the resolution

279 of the numerical grid. This analysis was performed by comparing outputs from a model

280 with grid resolution equal to that of geostatistical grid (about 4.6 million cells) to the

281 results of two models with horizontal resolutions that are two (about 18 million cells) and

282 four (about 78 million cells) times higher, respectively than the resolution of the

283 geostatistical grid. These models consider the $K$ field of the scenario with isotropic $L_{h}$

284 equal to $2 u_{h}$ (Group 1). No other scenarios of aquifer heterogeneity have been tested.

285 Since comparisons did not indicate significant differences, the model with grid resolution

286 equal to that of geostatistical grid was considered for flowmeter tests simulations.

287 Accordingly, the flowmeter well diameter is equal to the horizontal supporting scale of the 
289 imposed at the cells on the external surface $\Gamma_{D}$ of the cylindrical domain, while a

290 specified flux, simulating groundwater withdrawal at a constant rate $Q_{w}$, is applied at the

291 cell at the top of the vertical stack of cells representing the well. No-flow boundary

292 conditions are applied to all other boundaries. Following the approach used in previous

293 studies (e.g., Whittaker and Teutsch, 1999; Riva et al., 2012), a significantly large $K$ value

294 is assigned to the cells representing the well, with result of an equilibration of the

295 simulated heads (differences in the orders of $10^{-5}$ ). Because of this condition, discharge

296 into these cells depends only on the $K$ values of the neighbouring cells. Therefore, an

297 estimation of hydraulic conductivity for each cell can be calculated by applying Equation

298 (1), in way similar to a flowmeter test in a real aquifer. In this numerical simulation,

299 discharge values $\Delta Q_{i}$ from each layer $i$ into the well are provided from the cell-by-cell

300 balance of the groundwater flow model.

301 A series of assumptions are made in the calculation of the simulated $K$ estimates to

302 allow unbiased comparisons with the reference values. The first is that the measurement

303 interval of the simulated flowmeter tests corresponds to the vertical support scale of the

304 reference $K$ data $\left(1 u_{v}\right)$. With respect to the accuracy of the flowmeter $K$ estimates, this

305 represents a conservative condition because in field situations the thickness of aquifer

306 layers with different $K$ values is not known a priori. Moreover, studies have shown that

307 flowmeter estimates are sensitive to the choice of the measurement interval (Rehfeldt et

308 al., 1989; Molz et al. 1989; Boman et al. 1997; Whitteker and Teutsch, 1999). Two other

309 conservative assumptions are that estimated $K$ values are not affected by any source of

310 error other than numerical approximation, and that simulated flowmeter readings are not

311 bounded by a minimum detectable value, which studies suggest to be in the order of 0.005 
312 1/s (Rehfeldt et al., 1989; Young and Pearson, 1995). It is also assumed that the input

313 value in Equation (1) for the effective hydraulic conductivity of the aquifer $(\bar{K})$ is

314 calculated with the relationship (e.g., Sanchez-Vila et al., 2006):

$315 \quad \bar{K}=\frac{Q_{w}}{2 \pi Z\left(h_{D}-h_{w}\right)} \ln \left(\frac{r_{\Gamma_{D}}}{r_{w}}\right)$

316 where $h_{w}$ is the average hydraulic head in the well cells, the well radius $r_{w}$ is equal to 0.5

$317 u_{h}$, and $h_{D}$ is the head imposed at the boundary $\Gamma_{D}$ at a distance $r_{\Gamma_{D}}$ from the well $\left(120 u_{h}\right)$.

318 Because in Equation (1) $\bar{K}$ is a constant multiplicative factor, it can be shown that the

319 variance of the distribution of log-transformed $K$ estimates in the well cells is independent

320 of $\bar{K}$. Rather, different $\bar{K}$ values affect the mean of the distribution and produce shifts of

321 the vertical profile of log-transformed $K$ estimates toward lower or higher values.

322

323

\subsection{Validation criteria}

324 Simulated flowmeter $K$ data are validated through comparisons with reference data

325 based on the hydrofacies. For each scenario, the accuracy of the estimated $K$ values is

326 quantified by two different metrics. The first is the coefficient of determination $\left(\mathrm{R}^{2}\right)$

327 defined by the following:

$328 \quad R^{2}=1-\frac{\sum_{i=1}^{N}\left(Y_{R, i}-\overline{Y_{R}}\right)^{2}}{\sum_{i=1}^{N}\left(Y_{R, i}-Y_{F, i}\right)^{2}}$

329 where $Y_{R, i}$ is the log-transformed (base 10) reference $K$ value for the well cell $i, \bar{Y}_{R}$ is the

330 mean of the distribution of $Y_{R, i}, Y_{R, i}$ is the corresponding log-transformed flowmeter $K$

331 estimate, and $N=80$ is total number of well cells. The coefficient $\mathrm{R}^{2}$ is a measure of the

332 ability of the simulated flowmeter tests to reproduce the variability of the reference log- 
333 transformed $K$ profiles. Perfect variance recovery is indicated by an $\mathrm{R}^{2}$ equal to 1 .The

334 second metric is the average accuracy ratio $(Q)$ defined as:

$335 Q_{k}=\frac{1}{M} \sum_{i=1}^{M} \log _{10}\left(\frac{K_{F, i}^{k}}{K_{R, i}^{k}}\right)$

336 where $K_{R, i}^{k}$ is the reference $K$ value for hydrofacies $k, K_{F, i}^{k}$ is the corresponding

337 flowmeter estimate, and $M$ is the total number of reference $K$ data for hydrofacies $k$. For

338 each hydrofacies, $Q$ quantifies the average order of magnitude of difference between

339 reference and estimated $K$ values. A perfect match is achieved when $Q=0$.

\section{$341 \quad 3 \quad$ Results}

342 Calculated effective hydraulic conductivity $(\bar{K})$ of the reference $K$ fields are

343 presented in Table 1 normalized with respect to the characteristic $K$ of hydrofacies " $H$ "

$344\left(K_{H}\right)$. Corresponding normalized values of the harmonic and arithmetic means of the

345 distribution of reference $K$ values in the well cells are also reported to provide an

346 indication of the degree of stratification of the structure of $K$ fields. In fact, it can be

347 shown that these two types of means represent the effective hydraulic conductivity of 2-D

348 perfectly stratified systems - each having the same vertical $K$ distribution as that of the

349 well cells - in which flow is either perpendicular (harmonic mean) or parallel (arithmetic

350 mean) to the stratification. Calculated $\bar{K}$ values fall within these two bounds. In

351 particular, as the horizontal mean length of the hydrofacies increases, $\bar{K}$ tends towards

352 values more similar to the arithmetic mean indicating a corresponding increment in the

353 degree of stratification.

354 The variances of the distributions of $\log _{10}(K)$ and $\ln (K)$ for each scenario allow one

355 to compare the variability of the reference $K$ fields to that considered in other synthetic 
case studies (e.g., Zhang et al., 2013) or observed in the field (e.g., Rehfeldt et al., 1992;

357 Barahona-Palomo et al., 2011; Bohling et al., 2012). For the considered reference $K$ fields,

358 the variance of $\ln (K)$ varies between 1.1 and 16.3 depending on the $K_{H} / K_{L}$ ratio and on

359 the value of $\varepsilon_{d e}$ (Table 1). These values, which indicate a moderate to high level of

360 heterogeneity, are within the typical range of values observed in alluvial aquifers (Zhang

361 et al., 2013 and references therein).

\subsection{Impact of the mean length of the hydrofacies}

The impact of the isotropic horizontal mean length $L_{h}$ of the hydrofacies on the accuracy of the simulated flowmeter tests is analysed in eight scenarios. These correspond to reference $K$ fields having different structures (Figure $2 \mathrm{a}-2 \mathrm{~d}$ ), but identical univariate statistical distribution of $K$ values in the domain $\left(\sigma_{\ln K}^{2} \approx 4\right)$ as well as identical vertical profiles of $d_{e}$ and $K$ along the well. The shape of vertical $K$ profiles estimated with the simulated flowmeter test varies depending on the mean lengths of the hydrofacies and the degree of stratification in the reference $K$ fields (Figure 3). The comparison between estimated and reference $K$ data for architectures with short $L_{h}$ values ( $L_{h} \leq 4 u_{h}$ ) shows significant discrepancies. The sign of these is both positive and negative, as shown, for instance, by the overprediction of reference $K$ data between normalized elevations of 60 and 70, or by the overall underprediction of the characteristic $K$ of hydrofacies " $H$ ".

375 Moreover, the mismatch between estimated and reference $K$ profiles is equally noticeable even when the arithmetic mean of the reference $K$ values is used as the value assigned to $\bar{K}$ in Equation (1). This is analogous to assuming that the vertical $K$ distribution along the

378 profile is known a priori. For larger $L_{h}$ values $\left(L_{h} \geq 16 u_{h}\right)$, flowmeter estimates tend to match the reference $K$ values more accurately especially for the thick and horizontally 
continuous layers of similar conductivity that are intercepted by the testing well. However,

381 the reference conductivity of thin intervals with vertical extent of 1 or $2 u_{v}$ can only be

382 matched for the scenario with $L_{h}=\infty$. The practically perfect match between reference

383 and simulated $K$ profiles is a proof of the validity of the numerical results since this

384 scenario represents a benchmark problem for the numerical model.

385 Calculated values of $R^{2}$ range from -0.184 to 1.000 corresponding to the two extreme

386 scenarios with $L_{h}=1 u_{h}$ and $L_{h}=\infty$, respectively (Figure $4 \mathrm{a}$ ). $\mathrm{R}^{2}$ increases monotonically

387 with $L_{h}$ according to a relationship that can be described by the power law:

$388 \quad R^{2}=1-a L_{h}^{b}$

389 where the constant $a$ is positive and the exponent $b$ is negative. It is noteworthy that only

390 for scenarios with $L_{h}>16$ the calculated $\mathrm{R}^{2}$ values are higher than 0.75 . From the

391 interpretation of $\mathrm{R}^{2}$, this result shows that the simulated flowmeter tests are able to

392 characterize the true variability of the reference $K$ field only when the $K$ field structure has

393 a high degree of stratification near the testing location. For scenarios considering

394 imperfect stratification resulting from a more chaotic hydrofacies architecture (e.g., Figure

395 2a), simulated flowmeter data underpredict the true $K$ variability (see also Figure 3 ).

396 Calculated $Q$ values for the different structures are plotted in Figure 4b. Irrespective

397 of the type of hydrofacies, results show that the accuracy of the estimated $K$ values is

398 strongly dependent on the mean length of the hydrofacies and therefore on the aquifer

399 architecture. From our numerical experiment, the relationship between $Q$ and $L_{h}$ can also

400 approximated by a power law in the form:

$401 \quad Q_{k}=a_{k} L_{h}^{b_{k}}$

402 where the values of the constant $a$ and the exponent $b$ depend on the reference $K$ of

403 hydrofacies $k$. Comparisons between $Q$ values for the different hydrofacies indicates that 
the highest estimation errors are observed for the reference $K$ value of the most conductive hydrofacies " $\mathrm{H}$ " especially for scenarios considering short $L_{h}$, while the estimation error is more uniformly distributed in more stratified architectures. Even for the scenario corresponding to $L_{h}=64 u_{h}$ (Figure $2 \mathrm{c}$ ), the estimation error is still not negligible. In fact the average of the $Q$ values for the different hydrofacies is equal to 0.135 , which means that flowmeter $K$ estimates differ from the true $K$ values by a factor $\approx 1.3$ on average.

\subsection{Impact of the horizontal anisotropy ratio}

The effect of the anisotropy ratio $L_{y} / L_{x}$ is tested in five scenarios including an

413 isotropic base case with $L_{x}=L_{y}=4$ (Figure 2a) and four anisotropic scenarios in which

414 the mean length of the hydrofacies " $\mathrm{H}$ " and " $\mathrm{I}$ " in the $y$ direction $\left(L_{y}\right)$ is progressively

415 incremented up to a value equal to $64 u_{h}$. Examples of the generated $K$ fields are shown in 416 Figures $2 \mathrm{e}$ and $2 \mathrm{~b}$. The vertical $K$ profiles show that simulated flowmeter tests results are

417 sensitive with respect to the ratio $L_{y} / L_{x}$ (Figure 5), although discrepancies between

418 corresponding $K$ values for different scenarios appear quite random. Accordingly, the

419 goodness of fit of the estimated $K$ profiles does not seem to improve or decline substantially with the variation of the anisotropy ratio.

The relatively moderate impact of the horizontal anisotropy ratio of the hydrofacies

422 on the accuracy of the simulated flowmeter tests is confirmed by the analysis of the

423 accuracy metrics (Figure 6). An increment in $\mathrm{R}^{2}$ from the value corresponding to the 424 isotropic base case is observed in the first two anisotropic scenarios, which is particularly

425 steep between the points at $L_{y} / L_{x}=2$ and $L_{y} / L_{x}=4$. The maximum $\mathrm{R}^{2}$ value for the

426 scenario with $L_{y} / L_{x}=4$ is about $50 \%$ larger than the corresponding value in the isotropic

427 scenario. However, this increment in $\mathrm{R}^{2}$ is followed by a slow decline for larger 
anisotropy ratios as the $K$ structure becomes more and more characterized by elongated

429 forms (Figure 2f). Variations of $Q$ for the different hydrofacies (Figure 6b) indicate that

430 the increment in accuracy observed for scenarios with moderate anisotropy is particularly

431 evident for the extreme $K$ values $\left(K_{L}\right.$ and $\left.K_{H}\right)$, while $Q$ values for hydrofacies "I" are

432 generally stable for all the anisotropy ratios.

433 Simulations results indicate that the effective conductivity value $\bar{K}$ does not change

434 significantly in this group of scenarios (Table 1 and Figure 5). Accordingly, the horizontal

435 anisotropy ratio of the hydrofacies has little effect on the difference between $\bar{K}$ and the

436 arithmetic mean of the reference $K$ values, indicating that the overall degree of

437 stratification in the $K$ field structures is also relatively stable. This result can explain the

438 moderate effect of the anisotropy ratio on the accuracy of the flowmeter test simulations.

439 For brevity, only results for scenarios considering a short mean length of the hydrofacies

440 in the $x$ direction $\left(L_{x}=4\right)$ are presented here. However, a consistent behaviour is observed

441 also for scenarios considering larger $L_{x}$ values.

\section{$443 \quad 3.3$ Impact of the hydraulic conductivity contrast}

444 Accuracy metrics for scenarios with different $K$ contrasts between hydrofacies " $\mathrm{H}$ "

445 and "L" are shown in Figure 7. Results are presented for two architectures including one

446 with a relatively short horizontal mean length of the hydrofacies $\left(L_{h}=4 u_{h}\right)$, and a second

447 architecture characterized by a more stratified $K$ field structure $\left(L_{h}=16 u_{h}\right)$. For both

448 architectures, the analysis of the values of $\mathrm{R}^{2}$ shows that ability of the simulated flowmeter

449 tests to accurately represent the true $K$ variability declines as the ratio $K_{H} / K_{L}$ becomes

450 larger (Figure 7a). Numerical results seem to suggest a linear relationship between $\mathrm{R}^{2}$ and

451 the logarithm of the $K_{H} / K_{L}$ ratio. However, the impact of the $K_{H} / K_{L}$ ratio on $\mathrm{R}^{2}$ is 
452 slightly more evident for the architecture characterized by the largest $L_{h}$. On average, one

453 order of magnitude increment in the $K_{H} / K_{L}$ ratio for scenarios with $L_{h}=16 u_{h}$

454 corresponds to a $7 \%$ decline in $\mathrm{R}^{2}$, while the corresponding percentage for the scenarios

455 with $L_{h}=4 u_{h}$ is about $5 \%$.

456 When the accuracy of the flowmeter $K$ estimates is evaluated for the different

457 hydrofacies (Figure 7b), results indicate that the decline in accuracy for larger $K_{H} / K_{L}$

458 ratios is more apparent for architectures characterized by shorter mean lengths of the

459 hydrofacies especially for hydrofacies " $\mathrm{H}$ " and "L. For scenarios considering $L_{h}=4 u_{h}$,

460 for example, each order of magnitude of increment in the $K_{H} / K_{L}$ ratio correspond to a

4610.2 increment in $Q$. This means that the discrepancy between estimated and reference $K$

462 values increases by a factor of about 1.4 for each order of magnitude of increment in the

$463 K_{H} / K_{L}$ ratio. When the $K$ contrast between hydrofacies "H" and "L" is equal to 4 orders

464 of magnitude, the average mismatch between simulated and reference $K$ values is about

465 one order of magnitude. On the other hand, for the scenarios characterized by a more

466 stratified structure (i.e., $L_{h}=16 u_{h}$ ), $Q$ values are about one half of the corresponding

467 values for scenarios with $L_{h}=4 u_{h}$. As for the anisotropy ratio, the impact of the $K$

468 contrast on the accuracy of the flowmeter $K$ estimates is lower for hydrofacies with

469 intermediate conductivity.

$470 \quad 3.4$ Impact of intrafacies variability

471 The degree of sub-hydrofacies scale variability in the reference $K$ field is defined by

472 the value of the parameter $\varepsilon_{d e}$, which controls the range of the Gaussian distributions of the

473 effective diameter within the hydrofacies (Figure 8). The impact of intrafacies $K$

474 variability on the accuracy of the simulated flowmeter tests for different hydrofacies 
475 architectures is shown in Figure 9. In particular, the analysis of the variations of $\mathrm{R}^{2}$ with

476 increments of $\varepsilon_{d e}$ suggests that the ability of the flowmeter estimates to match the

477 variability of the reference $K$ is practically independent from the degree of intrafacies

478 variability expressed by $\varepsilon_{d e}$ (Figure 9a). It is possible that this result is influenced by the

479 approach used to model intrafacies variability, and that another approach may produce

480 more sensitive results.

481 Despite having negligible effect on the values of $\mathrm{R}^{2}$, intrafacies variability can still

482 impact the accuracy of the simulated $K$ estimates depending on type of hydrofacies

483 architecture. Calculated values of the accuracy metric $Q$ indicate that this impact is small

484 to almost negligible for scenarios characterized by shorter $L_{h}$ (e.g., Figure 9b), while it is

485 maximum for the scenario considering a perfectly stratified $K$ field (Figure 9c). In this

486 case, simulated results indicate a linear relationship between $Q$ and $\varepsilon_{d e}$.

4884 Discussion

$489 \quad 4.1$ Validity of estimated vertical $K$ profiles

490 Simulated vertical $K$ profiles are sensitive to the architecture and to some extent to the

491 sub-unit-scale lithological heterogeneity of the hydrofacies. In particular, the magnitude of

492 systematic errors observed in the flowmeter $K$ estimates depends on the degree of

493 deviation of the $K$ field structure from the conceptual model represented by a perfectly

494 stratified system. When the structure of the $K$ field differs from the stratified model,

495 systematic errors in the flowmeter $K$ estimates are introduced due to misinterpretations of

496 the measured discharge $\Delta Q_{i}$ from each measurement interval into the well. These

497 misinterpretations are caused by the presence of vertical flow components due to the non-

498 uniformity of the radial gradients surrounding the well (Figure 10). These components 
tend to increase the discharge from the less conductive hydrofacies "L" while reducing

500 discharge from the highly-conductive lithofacies " $\mathrm{H}$ ". The overall effect is a volume

501 averaging process of the true $K$ values around the well, which confirms the observations of

502 Zlotnik and Zurbuchen (2003b). Because of this process, $K$ is overestimated in the lower

$503 K$ intervals and it is underestimated in the higher- $K$ zones. This tendency has been

504 suggested by previous field studies (Molz et al., 1989; Bohiling et al., 2012) and

505 numerical analyses (Whittaker and Teutsch, 1999; Riva et al., 2012), but it was never

506 explained relative to the characteristics of the $K$ field structure. Because of this systematic

507 under-/overprediction of extreme values, the true $K$ variability along the vertical profile is

508 underestimated.

509 Comparisons between scenarios with different architecture indicate that the horizontal

510 mean length of the hydrofacies, which controls the lateral extension of the units and

511 therefore the degree of stratification of the $K$ field, has a particularly high impact on the

512 accuracy of flowmeter $K$ data. For the transition probability/Markov chain modelling

513 approach, mean length values are indicative of spatial correlation similar to the way the

514 variogram range relates to correlation length for variogram-based geostatistical analyses.

515 From direct observations of aquifer outcrops or the analysis borehole data, correlation

516 lengths of sedimentary units at the scale of hydrofacies in alluvial systems range from few

517 meters to few tens of meters (e.g., Jussel et al., 1994; Anderson et al., 1999; Whittaker and

518 Teutsch, 1999; Labolle and Fogg, 2001; Zappa et al., 2006; Bayer et al., 2011; Bianchi

519 and Zheng, 2016). Given such relatively short range of lengths, it is likely that the

520 structure of the $K$ field in alluvial aquifers rarely supports the stratified structure

521 assumption, and that systematic errors in flowmeter $K$ data are therefore not negligible in

522 most of field applications. This consideration may find confirmation in the lack of

523 correspondence observed in several field sites between flowmeter $K$ data and other $K$ data 
measured from aquifer samples, such as those based on grain-size analysis or permeameter tests (Boggs et al. 1990; Hess et al., 1992; Whitteker and Teutsch, 1999; Barahona-

526 Palomo et al., 2011; Gueting et al., 2015; Bianchi and Zheng, 2016).

\section{2 $\underline{\text { Validity of estimated statistical distributions }}$}

So far, reference $K$ data and corresponding estimates from simulated flowmeter tests

530 have been compared for a single vertical profile. To better evaluate the impact of aquifer

531 architecture on the univariate distribution of estimated $K$ values, we now present the

532 results of simulations of multiple flowmeter tests. For each scenario of aquifer

533 architecture, flowmeter data are collected in 13 closely spaced locations around the centre

534 of the domain (Figure 11). Similarly to the previously described simulations, these

535 scenarios also consider three hydrofacies with different conductivity (i.e., $K_{L}, K_{I}$, and $K_{H}$ ).

536 The ratio $K_{H} / K_{L}$ in the corresponding $K$ fields is assumed to be equal to $10^{2}$, while the

537 characteristic $K$ for the hydrofacies "I" is one order of magnitude lower than $K_{H}$.

538 Intrafacies variability of $K$ is also simulated assuming $\varepsilon_{d e}$ is equal to 0.3 for all the

539 hydrofacies. The structure of the reference $K$ fields for each scenario is controlled by the

540 aquifer architecture corresponding to a certain value of the isotropic mean length $L_{h}$.

541 However, all the reference $K$ fields share the same tri-modal univariate histogram (Figure

542 12a). Given the relatively short distance between the different testing locations, the

543 effective hydraulic conductivity of the aquifer is assumed to be the value calculated in the

544 well at the centre of the domain.

545 As shown in Figure 12a, reference $K$ values of the well cells at the test locations for a

546 total of more than a thousand values provide a representative sample of the $K$ distribution

547 in the entire domain. On the other hand, histograms of simulated flowmeter $K$ estimates 
548 differ substantially from that of the reference $K$ data. In particular, the tri-modal

549 distribution of the reference $K$ fields can be identified in the simulated flowmeter data

550 only in the two scenarios with $L_{h} \geq 16 u_{h}$. For architectures characterized by shorter $L_{h}$,

551 estimated $\log _{10}(K)$ values follow complex distributions with no immediately discernible

552 shape. The variance of $\log _{10}(K)$ values in these scenarios is also lower than the true

553 variance of the reference $K$ field. For instance, the true $\log _{10}(K)$ variance is

554 underestimated by factor $\approx 1.5$ in the scenario with $L_{h}=4$. Although a better match

555 between the variances of the reference and simulated $K$ data is obtained as $L_{h}$ increases,

556 the true variance is underestimated in all the scenarios. On the other hand, a comparison of

557 the mean values indicates that the aquifer architecture has little impact on the mean of the

558 flowmeter $K$ data. This is an interesting result, which may provide an explanation for the

559 similarity between mean values of flowmeter and grain-size based $K$ estimates at

560 coinciding locations in an alluvial aquifer near Tübingen (Germany), even though the

561 variance of the flowmeter $K$ data is lower than the corresponding grain-size based

562 estimates (Barahona-Palomo, 2011).

563 Previous studies have investigated the statistical distribution of the increments (i.e.,

564 the difference of values measured at two locations separated by a spatial lag) of hydraulic

565 conductivity (e.g., Liu and Molz, 1997; Lu and Molz, 2001; Meershaert et al., 2004;

566 Meershaert et al., 2013, Guadagnini et al. 2013), permeability (e.g., Painter, 1996; Castle

567 et al., 2004; Guadagnini et al., 2012; Riva et al., 2013; Siena et al., 2012), and other

568 hydrogeological and geophysical properties (e.g., Yang et al., 2009; Guadagnini et al.,

569 2013). Liu and Molz (1997), for example, analysed the distribution of $\ln (K)$ increments in

570 the extensive dataset of flowmeter measurements collected at the MADE site. Results

571 show that for a lag equal to the measurement interval $(\approx 0.15 \mathrm{~cm})$, the probability density 
572 function (PDF) of the increments exhibits a distinct peak around the mean equal to zero

573 and symmetric slow decaying tails, which can be reasonably described by a Lévy-stable

574 distribution (Samorodnitsky and Taqqu, 1994). This is a family of distributions

575 characterized by a Lévy index $\alpha$, with range $0-2$, which controls the power-law decay of

576 the tails of the PDF. For a Lévy index equal to 2, the Lévy distribution is Gaussian. Levy-

577 stable or similar heavy-tailed distributions of the increments have been observed in other

578 flowmeter $K$ data (Hess et al.,1992; Meershaert et al., 2004), as well as in $K$ and

579 permeability datasets based on other measurement techniques (Painter et al., 1996;

580 Guadagnini et al., 2013; Riva et al, 2013, among others). Lévy-stable or Lévy-like

581 distributions provide the mathematical basis for stochastic fractal-based models of

582 subsurface heterogeneity (see Molz et al., 2004 for a review).

583 PDFs of the distributions of increments of $\log _{10}(K)$ for the simulated flowmeter and

584 reference $K$ datasets are shown in Figure 13. Increments are calculated for lags equal to 1

$585 u_{v}$ along the vertical succession of cells in the 13 simulated flowmeter test locations, as

586 well as for all the vertical successions of cells in the entire domain. The distribution of the

587 increments in the reference $K$ field is characterized by five bell-shaped peaks, and clearly

588 reflects a number of features of the hydrofacies model and corresponding reference $K$ field

589 including 1) the number of hydrofacies, 2) their volumetric fractions, 3) juxtapositional

590 tendencies between hydrofacies, 4) the $K$ contrasts between hydrofacies, and 5) the chosen

591 model of intrafacies variability. This reference distribution is not discernible in the

592 distributions of $\log _{10}(K)$ increments in the simulated flowmeter data. Rather, especially

593 for scenarios with shorter $L_{h}$, the distribution of flowmeter based increments inaccurately

594 suggest a distribution characterized by zero mean and heavy tails, which can be reasonably

595 described by Lévy stable distributions with Lévy index $\alpha$ ranging from 0.677 to 1.009 . It

596 can be noted that the tails become heavier with increments of $L_{h}$. The implication of this 
result is twofold. First, it strongly suggests that the Lévy behaviour of the increments in

$598 \log (\mathrm{K})$ observed in $K$ datasets based on flowmeter measurements may be an artefact if the

$599 K$ field structure has a low degree of stratification. Lu et al. (2002) already showed that by

600 combining facies and fractal modelling approaches it is possible to create realizations of

601 the $K$ field in which, although the distribution of the $\ln (K)$ increments within the facies is

602 Gaussian, the distribution of the increments for the entire multi-facies domain follows a

603 Lévy like distribution. In this previous study, the Lévy behaviour was indicated as a

604 statistical artefact. On the other hand, the results of this study indicate the possibility that

605 the Lévy behaviour frequently observed in the distribution of $\log (K)$ increments may be

606 instead an artefact of the measurement method. The cause of this behaviour needs further

607 investigation, but it is possible that the main reason is the previously described

608 misinterpretation of the measured discharge values along the well by the traditional

609 flowmeter data interpretation. The resulting averaging mechanism causes a smoothing

610 effect of the true $K$ contrast along the profile and an artificial enhancement of the

611 correlation between estimated $K$ values at shorter lags. The effect of this smoothing effect

612 can be seen in the heavy tailing of the $\log (K)$ increments. The second implication of this

613 result is that it suggests that it might be possible to obtain insight about of the true $K$ field

614 structure and hydrofacies architecture from the interpretation of the shape of the

615 distribution of $\log (K)$ increments from flowmeter measurements. This hypothesis will be 616 tested in a future study.

\section{Conclusions}

618 Detailed simulations of steady-state convergent groundwater flow in three-

619 dimensional $K$ fields are performed in order to evaluate the impact of medium-scale

620 sedimentary architecture and small-scale heterogeneity on the validity of flowmeter data.

621 In particular, we focus on systematic errors that arise when the $K$ field structure differs 
622 from the hypothetical perfectly stratified conceptualization at the basis of the traditional

623 method for flowmeter test interpretation. The general finding of this work is that

624 flowmeter testing should not be applied in alluvial aquifers without a preliminary

625 knowledge of the structure of the $K$ field. The presented numerical analysis in fact shows

626 that the validity of the $K$ estimates strongly depends on the hydrofacies architecture of the

627 aquifer, as well as on conductivity contrasts between and within the hydrofacies. All these

628 features are controlled by parameters (e.g., mean lengths and volumetric fractions of the

629 hydrofacies, grain-size distribution, etc.) that can be measured from the analysis of aquifer

630 samples, lithological well logs, or from the application of indirect methods of subsurface

631 characterization. The result of this preliminary characterization should be used to inform

632 the decision regarding the identification of the best method for a fine-scale $K$ field

633 characterization.

634 Comparisons between simulated flowmeter estimates and reference data for scenarios 635 considering a range of architectures, medium-scale and small-scale $K$ variability also lead 636 to the following specific conclusions.

637 For $K$ fields having the same univariate distribution, but with different structures

638 corresponding to a range of values of the isotropic horizontal mean length of the

639 hydrofacies, significant systematic errors are observed for scenarios with shorter mean

640 lengths. Numerical results suggest that the relationships between accuracy metrics of the $K$

641 estimates and the mean length of the hydrofacies can be adequately described by power

642 laws. When the $K$ structure deviates from the hypothetical perfectly stratified system,

643 flowmeter $K$ data tend to overestimate the true $K$ in low-K intervals, while they tend to

644 underpredict reference values in high- $K$ intervals. As a result, the true $K$ variability is also

645 underestimated in the profiles. 
647 corresponding to a range of anisotropy ratios between the horizontal mean lengths of the

648 hydrofacies, the overall effect of the anisotropy ratio on the accuracy of the flowmeter $K$

649 estimates is moderate.

650 For $K$ fields sharing the same structure, but with different ranges in the $K$ distributions

651 resulting from different values of the $K$ ratio between the highest and lowest conductive

652 hydrofacies, the accuracy of the flowmeter estimates decreases linearly with the $K$ ratio in

653 a semilog scale. In particular, the highest effect on the accuracy of the $K$ estimates is

654 observed for the extremes of the reference $K$ distribution, while the effect is more

655 moderate for intermediate $K$ values.

656 Compared to the other considered properties, the overall effect of the intrafacies $K$ variability on accuracy of the flowmeter is negligible in terms of reproducibility of the 658 actual $K$ field variance. However, some level of intrafacies variability can produce non659 negligible systematic errors in the estimation of the $K$ profiles, even when the true 660 medium-scale $K$ structure approximates a perfectly stratified system.

661 The analysis of the datasets resulting from a combination of the $K$ estimates from 662 multiple simulated flowmeter tests indicate that different architectures can have a

663 significant impact on the predicted statistical distributions of the estimated $K$ values and of 664 the increments of $\log _{10}(K)$. In scenarios in which the $K$ field structure deviates

665 substantially from the perfectly stratified model, the shape of the histogram of the 666 flowmeter $\log (K)$ estimates disguises the shape of the true distribution of $\log (K)$ values

667 and underestimates its variance. However, the mean values of the two distributions are 668 generally comparable irrespective of the aquifer architecture. For these scenarios, the 669 distributions of the $\log _{10}(K)$ flowmeter increments are also significantly different from the 670 distribution of the increments in the reference $K$ field. When the $K$ field is characterized by 
imperfect stratification, the distribution of the log-transformed $K$ increments based on

672 flowmeter estimates tends to follow an apparent Lévy behaviour with zero mean and

673 symmetric heavy tailing that tends to become heavier with increasing horizontal mean

674 length of the hydrofacies.

675

676 Acknowledgments. This work was undertaken as part of the "Research Fellowship

677 Programme" funded by the British Geological Survey (Natural Environment Research

678 Council). Marco Bianchi publishes with the permission of the Executive Director of the

679 British Geological Survey. Three anonymous reviewers are acknowledged for providing

680 constructive comments that improved the paper.

681

682 References

683 Allen-King, R. M., R. M. Halket, D. R. Gaylord, and M. J. L. Robin (1998),

684 Characterizing the heterogeneity and correlation of perchloroethene sorption and

685 hydraulic conductivity using a facies-based approach, Water Resour. Res., 34(3), 385-

686 396, doi:10.1029/97WR03496.

687 Anderson, M. P. (1989), Hydrogeologic facies models to delineate large-scale spatial

688 trends in glacial and glacialfluvial sediments, Geol. Soc. Am. Bull., 101, 501-511.

689 Anderson, M, J. Aiken, E. Webb, and D. Mickelson (1999), Sedimentology and

690 hydrogeology of two braided stream deposits, Sedimentary Geology, 129, 187-199.

691 Barahona-Palomo, M., M. Riva, X. Sanchez-Vila, E. Vazquez-Sune, and A. Guadagnini

692 (2011), Quantitative comparison of impeller flowmeter and particle-size distribution

693 techniques for the characterization of hydraulic conductivity variability, Hydrogeol. J.,

694 19(3), 603-612, doi:10.1007/s10040-011-0706-5.

695 Bayer, P., P. Huggenberger, P. Renard, and A. Comunian (2011), Three-dimensional high

696 resolution fluvio-glacial aquifer analog: Part 1: Field study. Journal of Hydrology, 405

$697 \quad$ (1-2) (2011), pp. 1-9. 
698

699

700

701

702

703

704

705

706

707

708

709

710

711

712

713

714

715

716

717

718

719

720

721

722

723

724

725

726

727

728

729

Bianchi, M., C. Zheng, G.R. Tick, and S.M. Gorelick (2011a), Investigation of SmallScale Preferential Flow with a Forced-Gradient Tracer Test, Groundwater, 49, 503514, doi: 10.1111/j.1745-6584.2010.00746.

Bianchi, M., and C. Zheng (2016), A lithofacies approach for modeling non-Fickian solute transport in a heterogeneous alluvial aquifer, Water Resour. Res., 52, 552-565, doi:10.1002/2015WR018186.

Bohling, G.C., G. Liu, S.J. Knobbe, E.C. Reboulet, D.W. Hyndman, P. Dietrich, and J.J. Butler Jr. (2012), Geostatistical analysis of centimeterscale hydraulic conductivity variations at the MADE site, Water Resour. Res., 48,W02525, doi:10.1029/2011WR010791.

Boggs, J. M., S. C. Young, D. J. Benton, and Y. C. Chung (1990), Hydrogeologic characterization of the MADE site, Interim Rep. EN-6915, Electr. Power Res. Inst., Palo Alto, Calif.

Boman, G. K., Molz, F. J. and Boonec, K. D. (1997), Borehole Flowmeter Application in Fluvial Sediments: Methodology, Results, and Assessment. Ground Water, 35: 443450. doi:10.1111/j.1745-6584.1997.tb00104.X

Butler, J. J.Jr. (2005), Hydrogeological methods for estimation of spatial variations in hydraulic conductivity, in Hydrogeophysics, Water Sci. and Technol. Libr., vol. 50, edited by Y. Rubin, and S. S. Hubbard, pp. 23-58, Springer, New York.

Castle, J. W., F. J. Molz, S. Lu, and C. L. Dinwiddie (2004), Sedimentology and fractalbased analysis of permeability data, John Henry member, Straight Cliffs formation (upper cretaceous), Utah, U.S.A., Journal of Sedimentary Research, 74(2), 270 - 284.

Carle, S.F. (1999), T-PROGS: Transition Probability Geostatistical Software, version 2.1. Davis, California: University of California.

Carle, S.F., and G.E. Fogg (1996), Transition probability-based indicator geostatistics, Math. Geol., 28(4), 453-476.

Carle S.F., and G.E. Fogg (1997), Modeling spatial variability with one and multidimensional continuous-lag Markov chains, Math. Geol., 29(7), 891-918.

Carle S.F., E.M. LaBolle, G.S. Weissmann, D. VanBrocklin, and G.E. Fogg (1998), Geostatistical simulation of hydrostratigraphic architecture: a transition probability / Markov approach, in Concepts in Hydrogeology and Environmental Geology No. 2, SEPM Special Publication, p. 147-170. 
Cooper, H.H. and C.E. Jacob (1946), A generalized graphical method for evaluating formation constants and summarizing well field history, Am. Geophys. Union Trans., vol. 27 , pp. 526-534.

Crisman, S. A., Molz, Fred. J., Dunn, D. L. and Sappington, F. C. (2001), Application Procedures for the Electromagnetic Borehole Flowmeter in Shallow Unconfined Aquifers. Ground Water Monitoring \& Remediation, 21: 96-100. doi:10.1111/j.17456592.2001.tb00645.x.

Dell'Arciprete, D., R. Bersezio, F. Felletti, M. Giudici, A. Comunian, and Ph. Renard (2012), Comparison of three geostatistical methods for hydro-facies simulation: a test on alluvial sediments, Hydrogeology Journal, 20, 299-311. doi:10.1007/s10040-0110808-0.

Deutsch, C.V., and A.G. Journel (1998), GSLIB geostatistical software library and user's guide, 2nd ed., Oxford University Press, New York, 369p.

Dinwiddie, C. L., Foley, N. A. and Molz, F. J. (1999), In-Well Hydraulics of the Electromagnetic Borehole Flowmeter, Ground Water, 37: 305-315. doi:10.1111/j.1745-6584.1999.tb00988.x

Feehley C.E., C. Zheng, and F.J. Molz (2000), A dual-domain mass transfer approach for modeling solute transport in heterogeneous porous media, application to the MADE site, Water Resour. Res., 36(9), 2501-2515, doi:10.1029/2000WR900148.

Fiori, A., G. Dagan, I. Jankovic, and A. Zarlenga (2013), The plume spreading in the MADE transport experiment: Could it be predicted by stochastic models? Water Resour. Res., 49, 2497-2507, doi:10.1002/wrcr.20128.

Frei, S., J. H. Fleckenstein, S. J. Kollet, and R. M. Maxwell (2009), Patterns and dynamics of river-aquifer exchange with variably saturated flow using a fully coupled model, J. Hydrol., 375(3-4), 383-393, doi:10.1016/j.jhydrol.2009.06.038.

Fogg, G. E. (1986), Groundwater Flow and Sand Body Interconnectedness in a Thick, Multiple-Aquifer System, Water Resour. Res., 22(5), 679-694, doi:10.1029/WR022i005p00679.

Fogg, G.E., C.D. Noyes, and S.F. Carle (1998), Geologically based model of heterogeneous hydraulic conductivity in an alluvial setting, Hydrogeology Journal, 6(1), 131-43.

Fogg, G.E., S.F. Carle, and C. Green (2000), Connected-network paradigm for the alluvial aquifer system. In: Zhang, D., C.L. Winter, eds., Theory, modeling, and field 
investigation in hydrogeology: A special volume in honor of Shlomo P. Neuman's 60th birthday, Geological Society of America, Special paper 348, p. 25-42.

Gómez-Hernández, J. J., J. J. Butler Jr., and A. Fiori (2016), Groundwater transport in highly heterogeneous aquifers, Eos, 97, doi:10.1029/2016EO047263.

Guadagnini, A., M. Riva, and S. P. Neuman (2012), Extended power-law scaling of heavy-tailed random air-permeability fields in fractured and sedimentary rocks, Hydrol. Earth Syst. Sci., 16, 3249-3260, doi:10.5194/hess-16-3249-2012.

Guadagnini, A., S. P. Neuman, M. G. Schaap, and M. Riva (2013), Anisotropic statistical scaling of vadose zone hydraulic property estimates near Maricopa, Arizona, Water Resour. Res., 49, 8463-8479, doi:10.1002/2013WR014286.

Gueting, N., A. Klotzsche, J. van der Kruk, J. Vanderborght, H Vereecken, and A. Englert (2015), Imaging and characterization of facies heterogeneity in an alluvial aquifer using GPR full-waveform inversion and cone penetration tests, Journal of hydrology, 524, 680 - 695, doi. 10.1016/j.jhydrol.2015.03.030.

Harbaugh, A.W. (2005), MODFLOW-2005, The U.S. Geological Survey modular groundwater model- the Ground-Water Flow Process: U.S. Geological Survey Techniques and Methods 6-A16, variously $\mathrm{p}$.

Heinz, J., S. Kleineidam, G. Teutsch, and T. Aigner (2003), Heterogeneity patterns of quaternary glaciofluvial gravel bodies (SW-Germany): application to hydrogeology, Sedimentary Geology, 158 (1-2), 1-23.

Hess, K.M. (1989), Use of a borehole flowmeter to determine spatial heterogeneity of hydraulic conductivity and macrodispersion in a sand and gravel aquifer, Cape Cod, Massachusetts. In: Molz, F.J., Melville, J.G., Guven, O. (Eds.), Proceedings of the Conference on New Field Techniques for Quantifying the Physical and Chemical Properties of Heterogeneous Aquifers, Dallas, Texas, March 20-23, 1989, National Water Well Association, Dublin, OH, 497-508.

Hess, K. M., S. H. Wolf, and M. A. Celia (1992), Large-scale natural gradient tracer test in sand and gravel, Cape Cod, Massachusetts: 3. Hydraulic conductivity variability and calculated macrodispersivities, Water Resour. Res., 28(8), 2011-2027, doi:10.1029/92WR00668.

Hufschmied, P. (1986) Estimation of three-dimensional statistically anisotropic hydraulic conductivity field by means of single well pumping test combined with flowmeter measurements, Hydrogeologie, 2, 163-174. 
Illman, W. A., J. Zhu, A. J. Craig, and D. Yin (2010), Comparison of aquifer controlled laboratory sandbox study, Water Resour. Res., 46, W04502, doi:10.1029/2009WR007745.

800 Javandel, I., and P. A. Witherspoon (1969), A Method of Analyzing Transient Fluid Flow in Multilayered Aquifers, Water Resour. Res., 5(4), 856-869, doi:10.1029/WR005i004p00856.

Jussel, P., F. Stauffer, and T. Dracos (1994), Transport modeling in heterogeneous aquifers: 1. Statistical description and numerical generation of gravel deposits, Water Resour. Res., 30(6), 1803-1817, doi:10.1029/94WR00162.

Koutrouvelis, I. A. (1980), Regression-Type Estimation of the Parameters of Stable Laws, Journal of the American Statistical Association, 75(372), 918 - 928.

Koutrouvelis I. A. (1981), An Iterative Procedure for the estimation of the Parameters of

811 LaBolle E.M., and G.E. Fogg (2001), Role of molecular diffusion in contaminant

812 migration and recovery in an alluvial aquifer system, Transport Porous Media, 42 (1-2), $813 \quad 155-179$.

814 Lee, S.-Y., S. F. Carle, and G. E. Fogg (2007), Geologic heterogeneity and a comparison 815 of two geostatistical models: Sequential Gaussian and transition probability-based 816 geostatistical simulation, Adv. Water Resour., 30, 1914-1932,

817 doi:10.1016/j.advwatres.2007.03.005.

818 Li, W., Englert, A., Cirpka, O. A. and Vereecken, H. (2008), Three-Dimensional

819 Geostatistical Inversion of Flowmeter and Pumping Test Data. Ground Water, 46: 193820 201. doi:10.1111/j.1745-6584.2007.00419.x.

821 Liu, H. H., and F. J. Molz (1997), Comment on "Evidence for non-Gaussian scaling 822 behavior in heterogeneous sedimentary formations" by Scott Painter, Water Resour. 823 Res., 33(4), 907-908, doi:10.1029/96WR03788.

824 Lu, S., and F. J. Molz (2001), How well are hydraulic conductivity variations 825 approximated by additive stable processes? Advances in Environmental Research, 5, 39$826 \quad 45$. 
Lu, S., F. J. Molz, G. E. Fogg, and J. W. Castle (2002), Combining stochastic facies and

828 fractal models for representing natural heterogeneity, Hydrogeol. J., 10, 475-482, 829 doi:10.1007/s10040-002-0212-x.

830 Maliva, R.G. (2016), Aquifer Characterization Techniques, Schlumberger Methods in 831 Water Resources Evaluation Series No. 4, Springer, 617 pp.

832 Miall, A.D (2014), Fluvial Depositional Systems. Springer International Publishing, 316 833 pp, doi: 10.1007/978-3-319-00666-6.

834 Meerschaert, M. M., T. J. Kozubowski, F. J. Molz, and S. Lu (2004), Fractional Laplace 835 model for hydraulic conductivity, Geophys. Res. Lett., 31, L08501, 836 doi:10.1029/2003GL019320.

837 Meerschaert, M. M., M. Dogan, R. L. Van Dam, D. W. Hyndman, and D. A. Benson 838 (2013), Hydraulic conductivity fields: Gaussian or not?, Water Resour. Res., 49, 4730839 4737, doi:10.1002/wrcr.20376.

840 Molz, F. J., R. H. Morin, A. E. Hess, J. G. Melville, and O. Güven (1989), The Impeller 841 Meter for measuring aquifer permeability variations: Evaluation and comparison with 842 other tests, Water Resour. Res., 25(7), 1677-1683, doi:10.1029/WR025i007p01677.

843 Molz, F. J., H. Rajaram, and S. Lu (2004), Stochastic fractal-based models of 844 heterogeneity in subsurface hydrology: Origins, applications, limitations, and future 845 research questions, Rev. Geophys., 42, RG1002, doi:10.1029/2003RG000126.

846 Newhouse, M.W., Izbicki, J.A. and Smith, G.A. (2005), Comparison of velocity-log data 847 collected using impeller and electromagnetic flowmeters. Ground Water, 43: 434-438. 848 doi:10.1111/j.1745-6584.2005.0030.x

849 Paillet, F.L. (2004), Borehole flowmeter applications in irregular and large diameter 850 boreholes, Journal of Applied Geophysics 55, no.1-2: 39-59.

851 Painter, S. (1996), Evidence for Non-Gaussian Scaling Behavior in Heterogeneous

852 Sedimentary Formations, Water Resour. Res., 32(5), 1183-1195,

853 doi:10.1029/96WR00286.

854 Ramanathan, R., R. W. Ritzi Jr., and R. M. Allen-King (2010), Linking hierarchical stratal 855 architecture to plume spreading in a Lagrangian-based transport model: 2. Evaluation 856 using new data from the Borden site, Water Resour. Res., 46, W01510, 857 doi:10.1029/2009WR007810. 
Rehfeldt, K.R., Hufschmied, P., Gelhar, L.W., Schaefer, M.E. (1989), The borehole flowmeter technique for measuring hydraulic conductivity variability, Report No. EN 6511, Electric Power Research Institute, Palo Alto, CA.

Rehfeldt, K. R., J. M. Boggs, and L. W. Gelhar (1992), Field study of dispersion in a heterogeneous aquifer: 3. Geostatistical analysis of hydraulic conductivity, Water Resour. Res., 28(12), 3309-3324, doi:10.1029/92WR01758.

Riva, M., L. Guadagnini, A. Guadagnini, T. Ptak, and E. Martac (2006), Probabilistic study of well capture zones distribution at the Lauswiesen field site J. Contam. Hydrol., 88 (1-2), 92-118.

Riva, M., A. Guadagnini, D. Fernadez-Garcia, X. Sánchez-Vila, and T. Ptak (2008), Relative importance of geostatistical and transport models in describing heavily tailed breakthrough curves at the Lauswiesen site, J. Contam. Hydrol., 101, 1-13, doi:10.1016/j.jconhyd.2008.07.004.

Riva, M., Ackerer, P., and Guadagnini, A. (2012), Interpretation of flowmeter data in heterogeneous layered aquifers, Journal of Hydrology, 452-453, 76-82.

Riva, M., S.P. Neuman, and A. Guadagnini (2013), Sub-Gaussian model of processes with heavy tailed distributions applied to permeabilities of fractured tuff. Stoch. Environ. Res. Risk Assess., 27, 195-207.

Ruud, N. C., and Z. J. Kabala (1996), Numerical Evaluation of Flowmeter Test Interpretation Methodologies, Water Resour. Res., 32(4), 845-852, doi:10.1029/96WR00004.

Ruud, N. C., and Z. J. Kabala (1997), Numerical evaluation of the flowmeter test in a layerd aquifer with a skin zone. Interpretation Methodologies, Water Resour. Res., 32(4), 845-852, doi:10.1029/96WR00004.

Ruud, N.C. , Z.J. Kabala, and F.J. Molz (1999), Evaluation of flowmeter-head loss effects in the flowmeter test, J. Hydrol., 224, 55-63.

Salamon, P., D. Fernandez-Garcia, and J. J. Gómez-Hernández (2007), Modeling tracer transport at the MADE site: The importance of heterogeneity, Water Resour. Res., 43, W08404, doi:10.1029/2006WR005522.

Samorodnitsky, G., and Taqqu, M.S. (1994), Stable non-Gaussian Random Processes, Chapman \& Hall, New York. 
890 conductivities in saturated groundwater flow, Rev. Geophys., 44, RG3002, 891 doi:10.1029/2005RG000169.

892 Scheibe, T. D., and D. L. Freyberg (1995), Use of sedimentological information for 893 geometric simulation of natural porous media structure, Water Resour. Res., 31(12), 894 3259-3270, doi:10.1029/95WR02570.

895 Siena, M., A. Guadagnini, M. Riva, and S. P. Neuman (2012), Extended power-law 896 scaling of air permeabilities measured on a block of tuff, Hydrol. Earth Syst. Sci., 16, 897 29-42, doi:10.5194/hess-16-29-2012.

898 Siirila-Woodburn, E. R., and R. M. Maxwell (2015), A heterogeneity model comparison 899 of highly resolved statistically anisotropic aquifers, Adv. Water Resour., 75, 53-66, 900 doi:10.1016/j.advwatres.2014.10.011.

901 Theis, C.V. (1935), The relation between the lowering of the piezometric surface and the 902

918 Weissmann, G.S., S.F. Carle and G.E. Fogg (1999). Three-dimensional hydrofacies

919 modeling based on soil surveys and transition probability Geostatistics. Water Resour. 920 Res., 35(6), 1761-1770. 
921 Wen X.H., and J. Gomez-Hernandez (1998), Numerical modeling of macrodispersion in

922 heterogeneous media: a comparison of multi-Gaussian and nonmulti-Gaussian models.

923 J. Contaminant Hydrol., 30(1-2), 129-56.

924 Western, A. W., G. Blöschl, and R. B. Grayson (2001), Toward capturing hydrologically

925 significant connectivity in spatial patterns, Water Resour. Res., 37(1), 83-97,

926 doi:10.1029/2000WR900241.

927 Whittaker, J., and G. Teutsch (1999), Numerical simulation of subsurface characterization

928 methods: Application to a natural aquifer analogue, Adv. Water Resour., 22(8), 819-

929829.

930 Xiang, J. (1995), The evaluation of the flowmeter test in three-layer aquifers and the

931 influence of disturbed zones, J. Hydrol., 166, 127-145.

932 Yang, C.-Y., K.-C. Hsu, and K.-C. Chen, (2009), The use of the Levy-stable distribution

933 for geophysical data analysis, Hydrogeology Journal, 17, 1265-1273,

934 doi:10.1007/s10040-008-0411-1.

935 Young, S. C. (1995), Characterization of High-K Pathways by Borehole Flowmeter and

936 Tracer Tests. Ground Water, 33: 311-318. doi:10.1111/j.1745-6584.1995.tb00286.x.

937 Young, S. C. and Pearson, H. S. (1995), The Electromagnetic Borehole Flowmeter:

938 Description and Application. Groundwater Monitoring \& Remediation, 15: 138-147.

939 doi: 10.1111/j.1745-6592.1995.tb00561.x.

940 Zappa, G., R. Bersezio, F. Felletti, and M. Giudici (2006), Modeling aquifer

941 heterogeneity at the facies scale in gravel-sand braided stream deposits. Journal of

942 Hydrology, 325, 1 - 4, $134-153$.

943 Zhang, Y., C.T. Green, and G. Fogg (2013), The impact of medium architecture of alluvial

944 settings on non-Fickian transport, Adv. Water Resour., 54, 78-99.

945 Zheng, C., M. Bianchi, and S.M. Gorelick (2011), Lessons learned from 25 years of

946 research at the MADE site, Groundwater, 49, 649-662, doi:10.1111/j.1745-

$947 \quad$ 6584.2010.00753.x.

948 Zinn, B., and C. F. Harvey (2003), When good statistical models of aquifer heterogeneity

949 go bad: A comparison of flow, dispersion, and mass transfer in connected and

950 multivariate Gaussian hydraulic conductivity fields, Water Resour. Res., 39, 1051,

951 doi:10.1029/2001WR001146, 3. 
952 Zlotnik, V.A., and B.R. Zurbuchen (2003a), Estimation of hydraulic conductivity from

953 borehole flowmeter tests considering head losses. Journal of Hydrology 281, no. 1-2: $954 \quad 115-128$.

955 Zlotnik, V. A., and B. R. Zurbuchen (2003b), Field study of hydraulic conductivity in a 956 heterogeneous aquifer: Comparison of single-borehole measurements using different 957 instruments, Water Resour. Res., 39(4), 1101, doi:10.1029/2002WR001415. 958

959 
960 Table 1. Scenarios of aquifer architecture and small-scale heterogeneity. The mean

961 thickness $L_{z}$ of the hydrofacies is equal to $2 u_{v}$ for all scenarios. HM: harmonic mean; AM:

962 arithmetic mean. $K_{H}$ and $K_{L}$ are the characteristic $K$ values of hydrofacies "H" and "L",

963 respectively. The characteristic $K$ of hydrofacies "I" is one order of magnitude smaller

964 than $K_{H}$.

965

\begin{tabular}{|c|c|c|c|c|c|c|c|c|c|}
\hline $\begin{array}{l}\text { Scenario } \\
\text { ID }\end{array}$ & $L_{x}\left[u_{h}\right]$ & $L_{y} / L_{x}$ & $\varepsilon_{\mathrm{de}}$ & $K_{H} / K_{L}$ & $\mathrm{HM} / K_{H}$ & $\bar{K} / K_{H}$ & $\mathrm{AM} / K_{H}$ & $\sigma_{\ln K}$ & $\sigma_{\log 10 K}$ \\
\hline \multicolumn{10}{|c|}{ Group 1: Variable isotropic horizontal mean length } \\
\hline $\mathrm{L} \_1$ & 1 & 1 & 0.0 & $10^{2}$ & 0.017 & 0.098 & 0.331 & 4.034 & 0.761 \\
\hline L 2 & 2 & 1 & 0.0 & $10^{2}$ & 0.017 & 0.125 & 0.331 & 4.034 & 0.761 \\
\hline L_4 & 4 & 1 & 0.0 & $10^{2}$ & 0.017 & 0.164 & 0.331 & 4.034 & 0.761 \\
\hline L_ 8 & 8 & 1 & 0.0 & $10^{2}$ & 0.017 & 0.221 & 0.331 & 4.034 & 0.761 \\
\hline L_16 & 16 & 1 & 0.0 & $10^{2}$ & 0.017 & 0.254 & 0.331 & 4.034 & 0.761 \\
\hline L_32 & 32 & 1 & 0.0 & $10^{2}$ & 0.017 & 0.261 & 0.331 & 4.034 & 0.761 \\
\hline L 64 & 64 & 1 & 0.0 & $10^{2}$ & 0.017 & 0.301 & 0.331 & 4.034 & 0.760 \\
\hline L_inf & $\infty$ & 1 & 0.0 & $10^{2}$ & 0.017 & 0.323 & 0.331 & 4.034 & 0.813 \\
\hline \multicolumn{10}{|c|}{ Group 2: Anisotropy ratio $L_{y} / L_{x}$} \\
\hline AR 1 & 4 & 1 & 0.0 & $10^{2}$ & 0.017 & 0.169 & 0.331 & 4.034 & 0.761 \\
\hline AR 22 & 4 & 2 & 0.0 & $10^{2}$ & 0.017 & 0.205 & 0.331 & 4.034 & 0.761 \\
\hline AR_ 4 & 4 & 4 & 0.0 & $10^{2}$ & 0.017 & 0.204 & 0.331 & 4.034 & 0.761 \\
\hline AR_8 & 4 & 8 & 0.0 & $10^{2}$ & 0.017 & 0.196 & 0.331 & 4.034 & 0.761 \\
\hline $\mathrm{AR} \_16$ & 4 & 16 & 0.0 & $10^{2}$ & 0.017 & 0.211 & 0.331 & 4.034 & 0.761 \\
\hline \multicolumn{10}{|c|}{ Group 3: $K_{H} / K_{I}$ ratio } \\
\hline L4_K1 & 4 & 1 & 0.0 & $10^{1}$ & 0.139 & 0.261 & 0.381 & 1.115 & 0.210 \\
\hline L4_K2 & 4 & 1 & 0.0 & $10^{2}$ & 0.017 & 0.165 & 0.331 & 4.031 & 0.760 \\
\hline L4_K3 & 4 & 1 & 0.0 & $10^{3}$ & 0.002 & 0.142 & 0.326 & 9.598 & 1.810 \\
\hline L4_K4 & 4 & 1 & 0.0 & $10^{4}$ & 0.0002 & 0.138 & 0.325 & 17.816 & 3.360 \\
\hline L16 K1 & 16 & 1 & 0.0 & $10^{1}$ & 0.139 & 0.339 & 0.381 & 1.115 & 0.210 \\
\hline L16_K2 & 16 & 1 & 0.0 & $10^{2}$ & 0.017 & 0.255 & 0.331 & 4.031 & 0.760 \\
\hline L16_K3 & 16 & 1 & 0.0 & $10^{3}$ & 0.002 & 0.223 & 0.326 & 9.598 & 1.811 \\
\hline L16_K4 & 16 & 1 & 0.0 & $10^{4}$ & 0.0002 & 0.215 & 0.325 & 17.816 & 3.361 \\
\hline \multicolumn{10}{|c|}{ Group 4: Intrafacies $K$ variability } \\
\hline L2_ede00 & 2 & 1 & 0.0 & $10^{4}$ & 0.0002 & 0.066 & 0.314 & 16.121 & 3.041 \\
\hline L2_ede 20 & 2 & 1 & 0.2 & $10^{4}$ & 0.0002 & 0.066 & 0.321 & 16.139 & 3.044 \\
\hline L2_cde40 & 2 & 1 & 0.4 & $10^{4}$ & 0.0002 & 0.066 & 0.331 & 16.196 & 3.055 \\
\hline L2_cde60 & 2 & 1 & 0.6 & $10^{4}$ & 0.0002 & 0.065 & 0.344 & 16.301 & 3.074 \\
\hline L2 $\varepsilon$ de 80 & 2 & 1 & 0.8 & $10^{4}$ & 0.0002 & 0.063 & 0.361 & 16.488 & 3.110 \\
\hline Linf_ede0 & $\infty$ & 1 & 0.0 & $10^{4}$ & 0.0002 & 0.259 & 0.265 & 14.684 & 2.770 \\
\hline Linf_ede20 & $\infty$ & 1 & 0.2 & $10^{4}$ & 0.0002 & 0.263 & 0.285 & 14.707 & 2.774 \\
\hline Linf $\varepsilon$ de 40 & $\infty$ & 1 & 0.4 & $10^{4}$ & 0.0002 & 0.266 & 0.308 & 14.765 & 2.785 \\
\hline Linf $\varepsilon$ de 60 & $\infty$ & 1 & 0.6 & $10^{4}$ & 0.0002 & 0.268 & 0.334 & 14.875 & 2.805 \\
\hline Linf_ede 80 & $\infty$ & 1 & 0.8 & $10^{4}$ & 0.0002 & 0.268 & 0.364 & 15.062 & 2.841 \\
\hline
\end{tabular}

966

967 


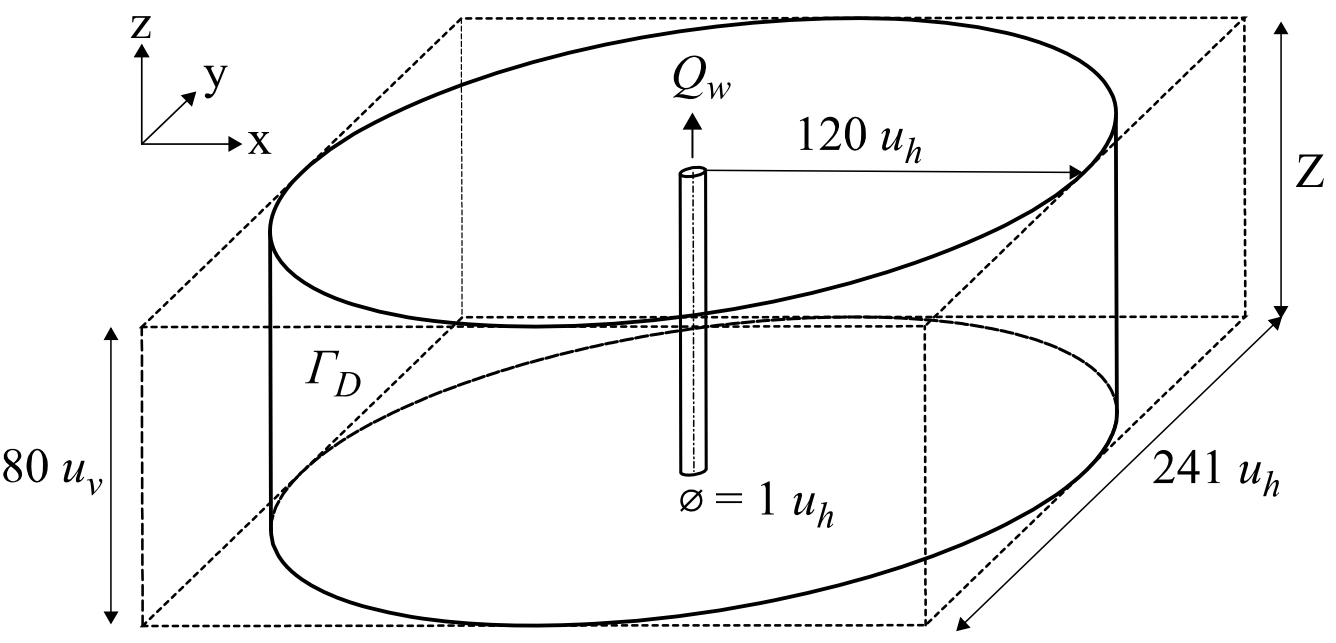

968

969

970 Figure 1. Geostatistical (dashed lines) and numerical (solid lines) domains used for

971 simulations of aquifer architecture and flowmeter tests. Both domains are discretized with

972 a block centered regular grid with cells of volume equal to $1 u_{h} \times 1 u_{h} \times 1 u_{v}$. The well for

973 flowmeter test simulation is located at the centre of the two domains.

974 
(a) $L_{h}=4 u_{h}$

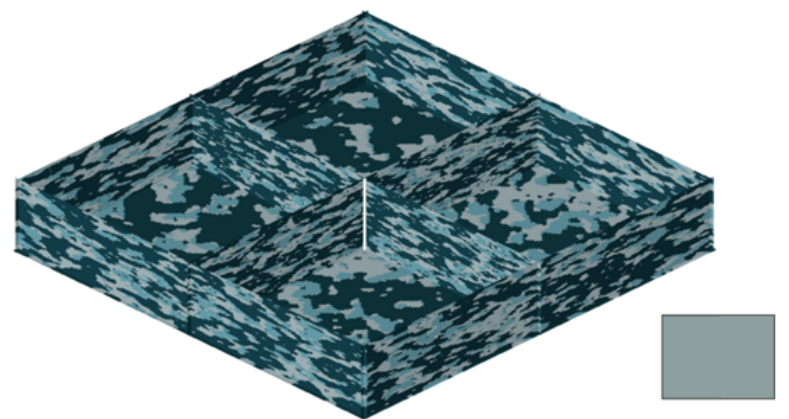

(c) $L_{h}=64 u_{h}$

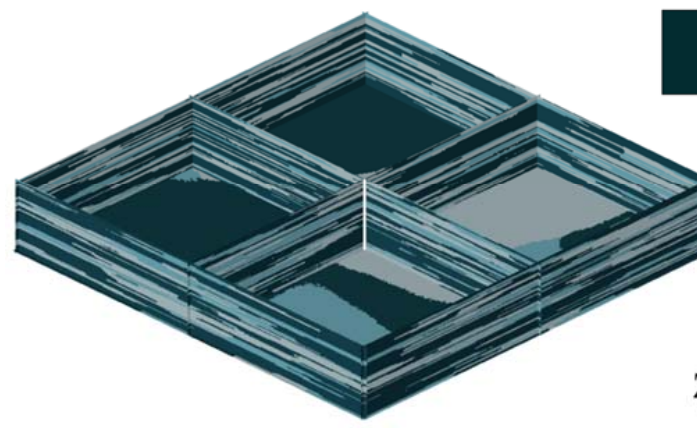

(e) $L_{y} / L_{x}=4$

975

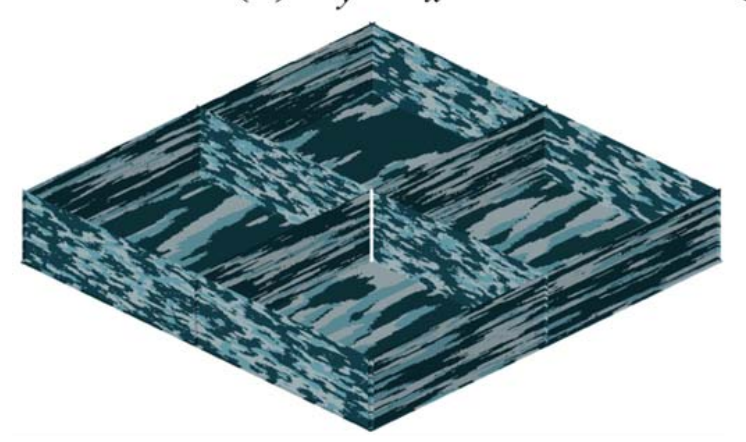

(b) $L_{h}=16 u_{h}$

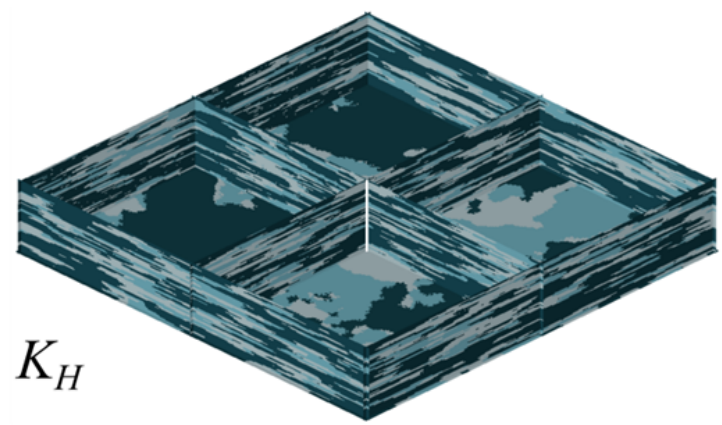

$K_{I}$

(d) $L_{h}=\infty$

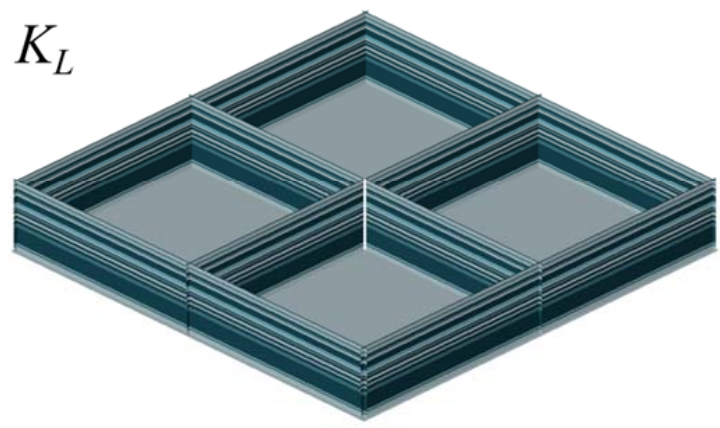

(f) $L_{y} / L_{x}=16$

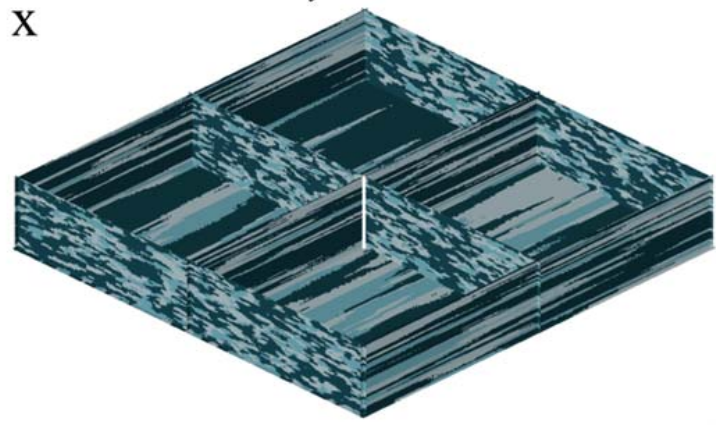

976

977 Figure 2. Hydraulic conductivity fields having identical univariate histogram of the $K$

978 values, identical vertical $K$ profile along the well for flowmeter simulations (shown as a

979 white line), but different structure according to value of the horizontal mean length $L_{h}$ and

980 anisotropy ratio $L_{y} / L_{x}$. 


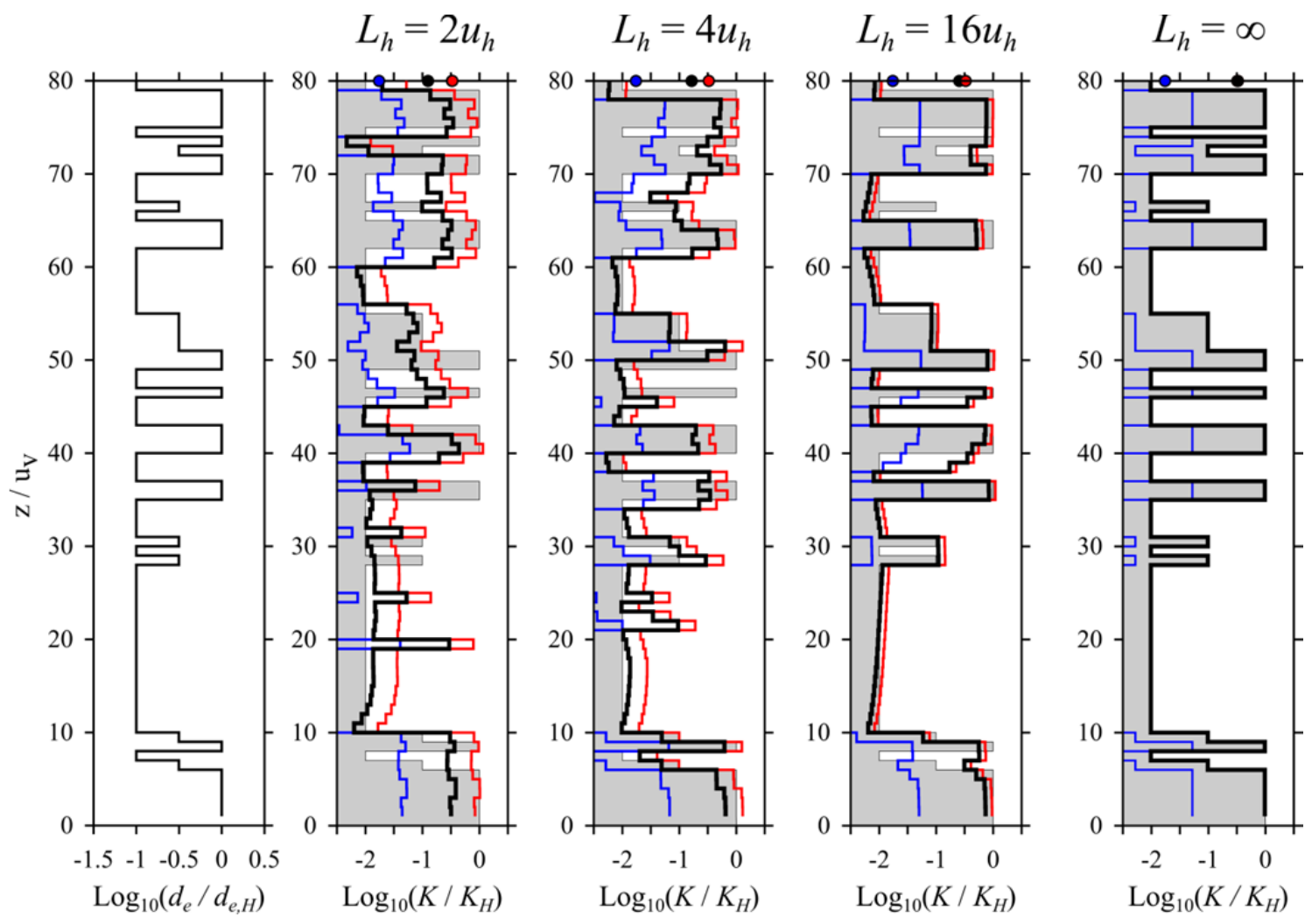

983

984 Figure 3. Vertical profile of the effective diameter $d_{e}$ (normalized by the $d_{e}$ of hydrofacies

985 "H”) and estimated vs. reference $K$ profiles for scenarios considering different $L_{h}$ values.

986 The reference $K$ profile is indicated by the shaded area. Mean and effective $K$ values are

987 plotted as circles of different colours: blue for harmonic mean; black for $\bar{K}$, and red for

988 arithmetic mean. Simulated flowmeter $K$ profiles considering these mean or effective $K$

989 values in Equation (1) are plotted as solid lines of corresponding colours. 

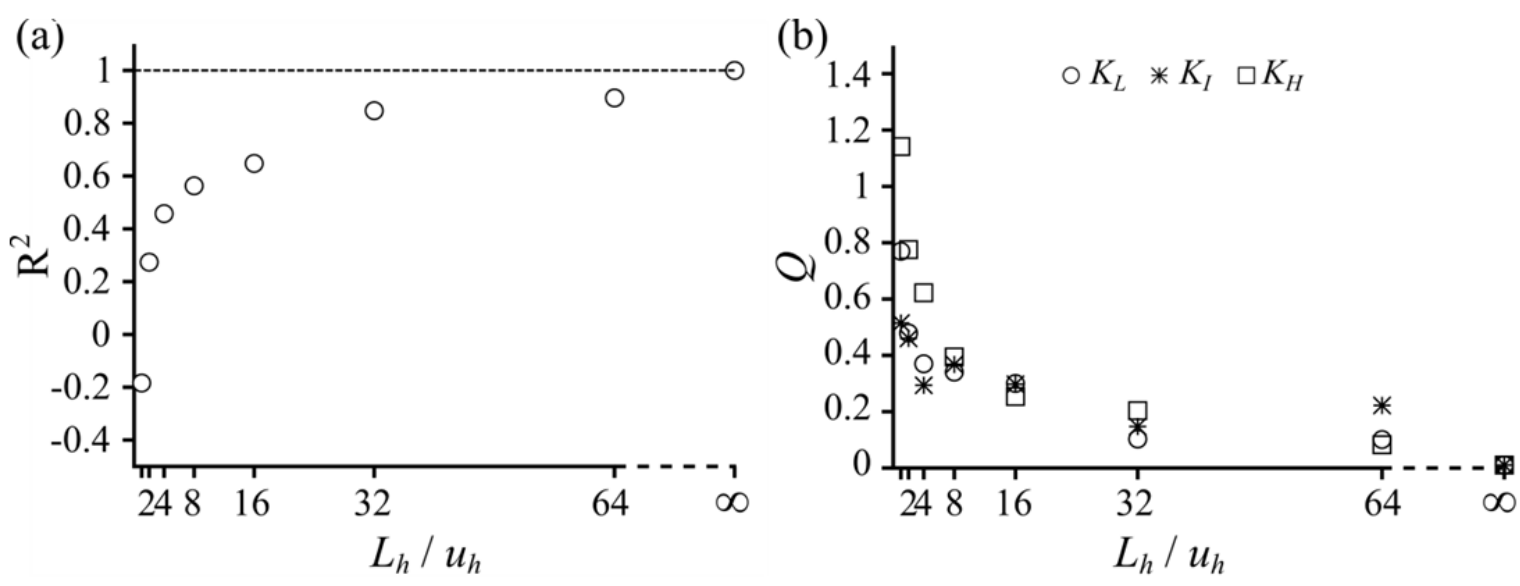

992 Figure 4. Variations of the accuracy metrics of flowmeter estimates with respect to the $L_{h}$

993 of the hydrofacies. (a) Coefficient of determination $\left(\mathrm{R}^{2}\right)$. (b) Average accuracy ratio $(Q)$. 


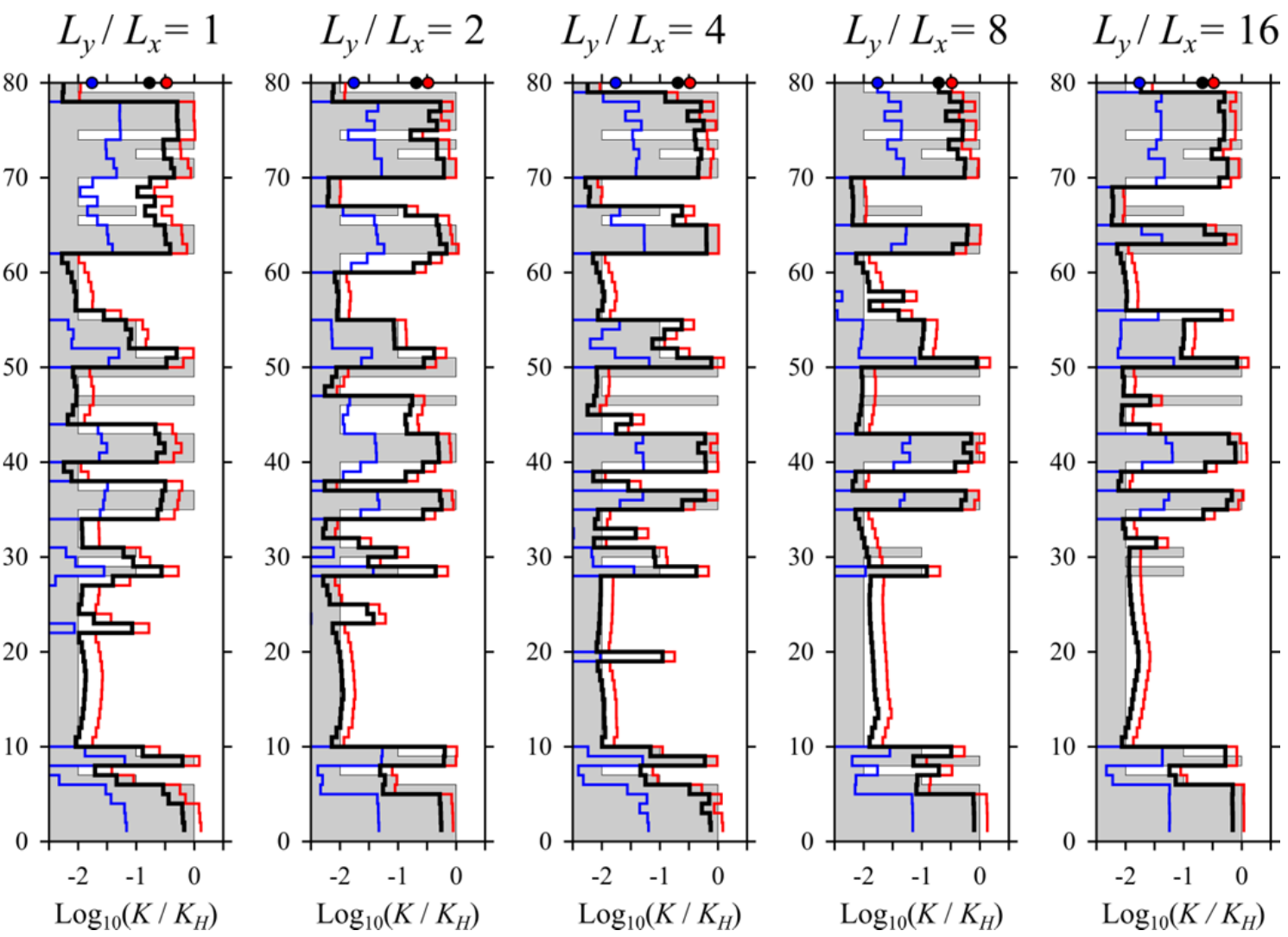

995

996 Figure 5. Estimated vs. reference $K$ profiles for scenarios considering different horizontal

997 anisotropy ratios. Refer to the caption of Figure (3) for the meaning of the colours and 998 symbols. 
(a)

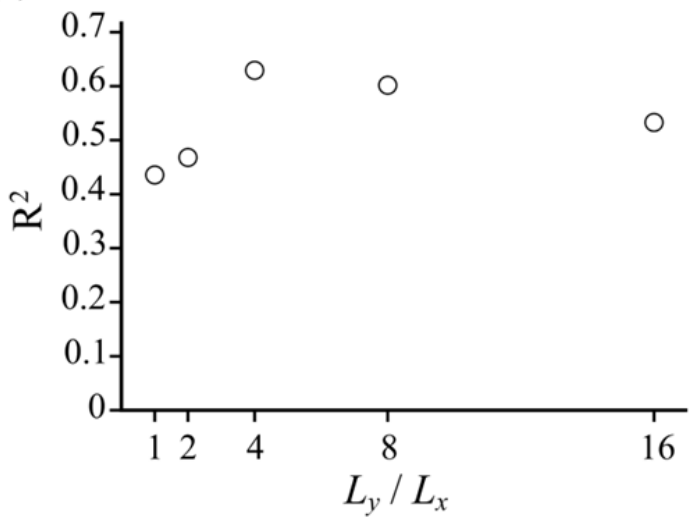

(b)

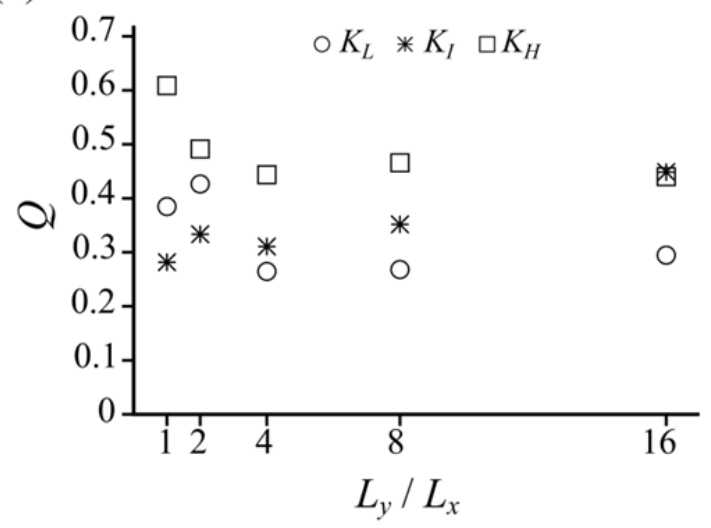

1000 Figure 6. Variations of the accuracy metrics of flowmeter estimates with respect to the 1001 anisotropy ratio. (a) Coefficient of determination $\left(\mathrm{R}^{2}\right)$. (b) Average accuracy ratio $(Q)$. 
(a)

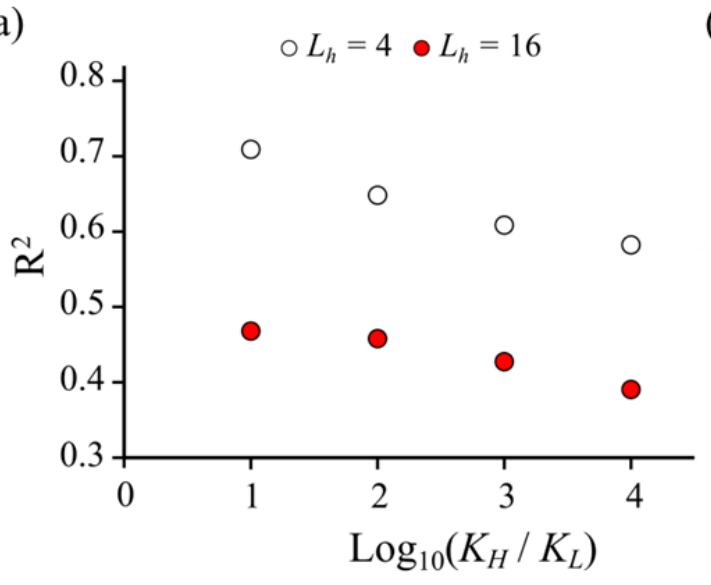

(b)

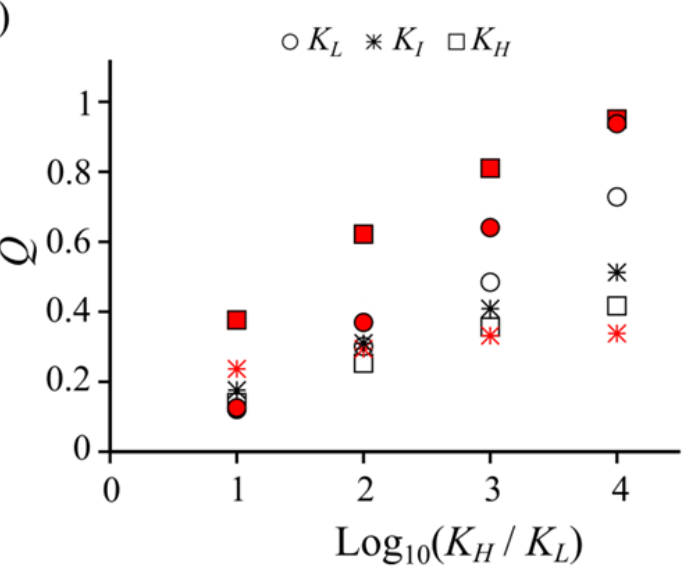

1003

1004 Figure 7. Variation of the accuracy metrics of flowmeter estimates with respect to the $K$ 1005 contrasts between hydrofacies " $\mathrm{H}$ " and " $\mathrm{L}$ " in two architectures. (a) Coefficient of 1006 determination $\left(\mathrm{R}^{2}\right)$. (b) Average accuracy ratio $(Q)$. The colours of the symbols in (b) 1007 correspond the legend of $L_{h}$ values in (a). 
(a)

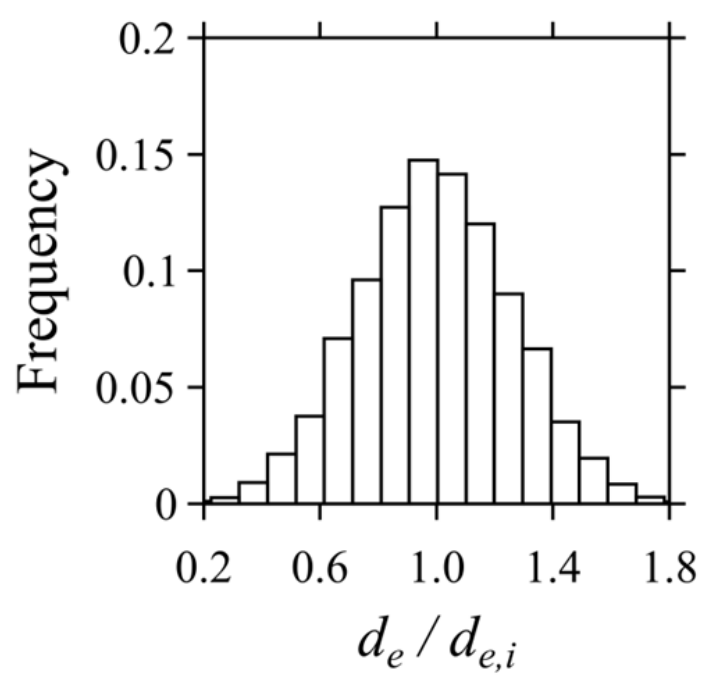

(b)

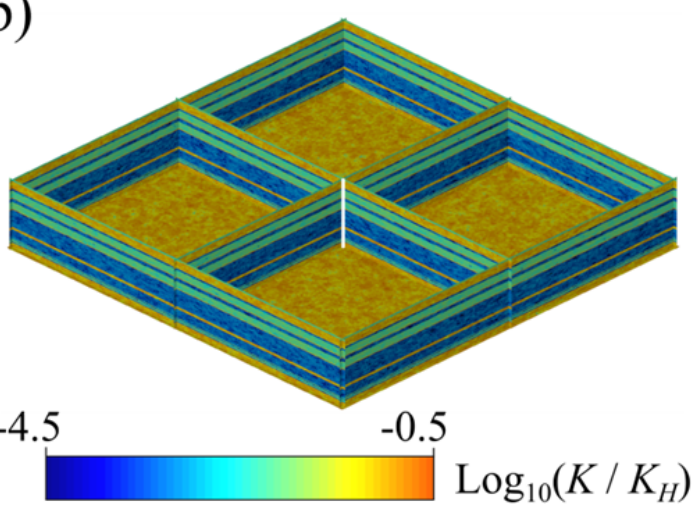

(c)

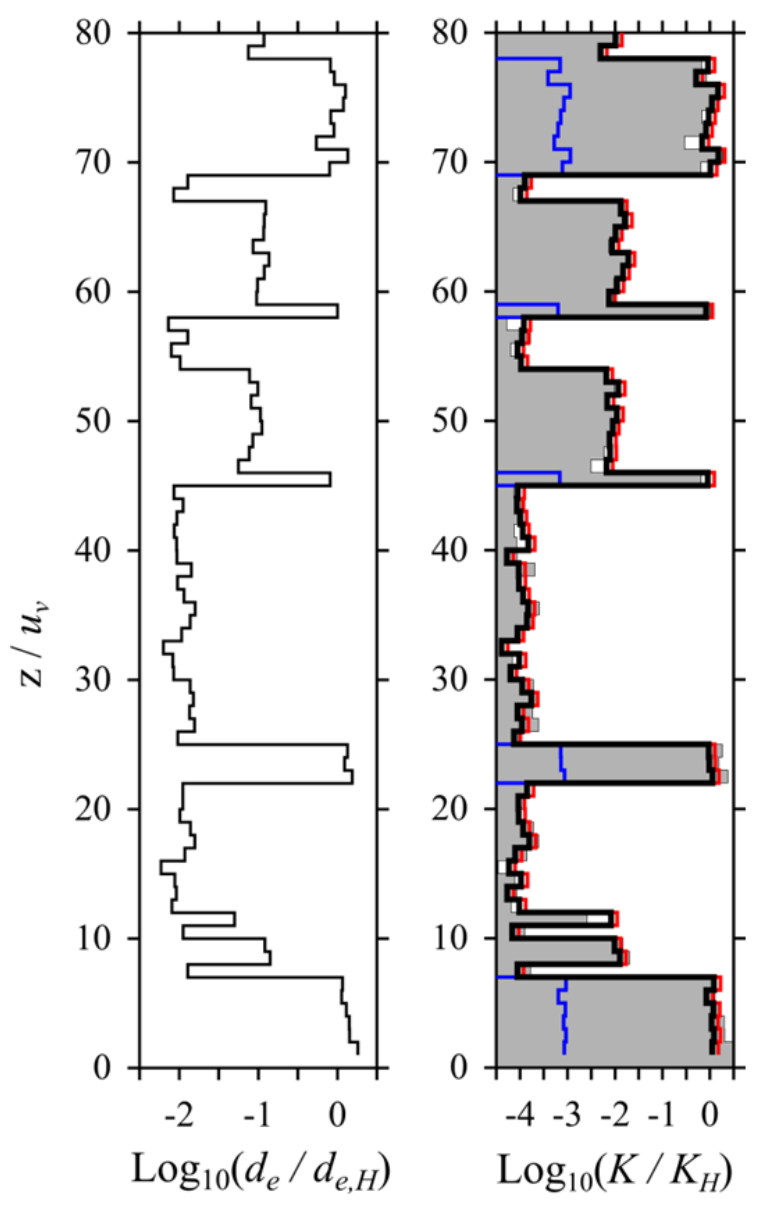

1010

1011

1012 Figure 8. Example of simulation of intrafacies $K$ variability (Scenario Linf_Ede08). (a)

1013 Histogram of normalized $d_{e} . d_{e, i}$ is the average effective diameter of a generic hydrofacies

$1014 i$. (b) $K$ field. (c) Vertical profile of normalized $d_{e}$ (left) and reference vs. flowmeter

1015 simulated $K$ profiles (right). Refer to the caption of Figure (3) for the meaning of the 1016 colours.

1017 
(a)

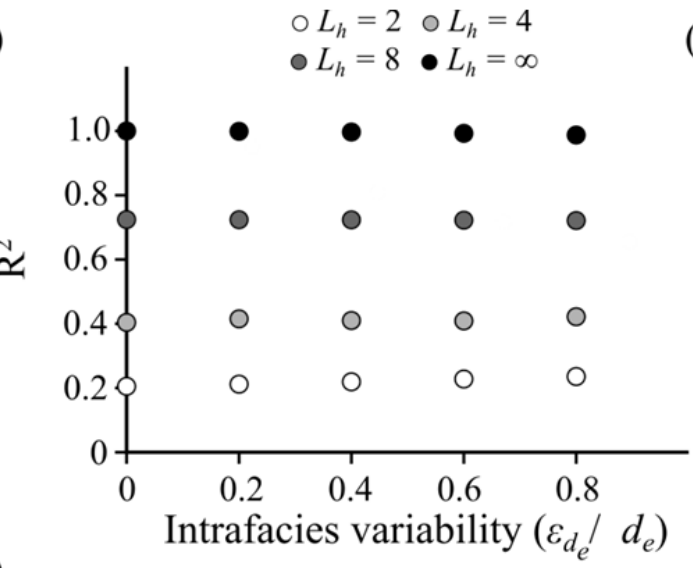

(c)

1018

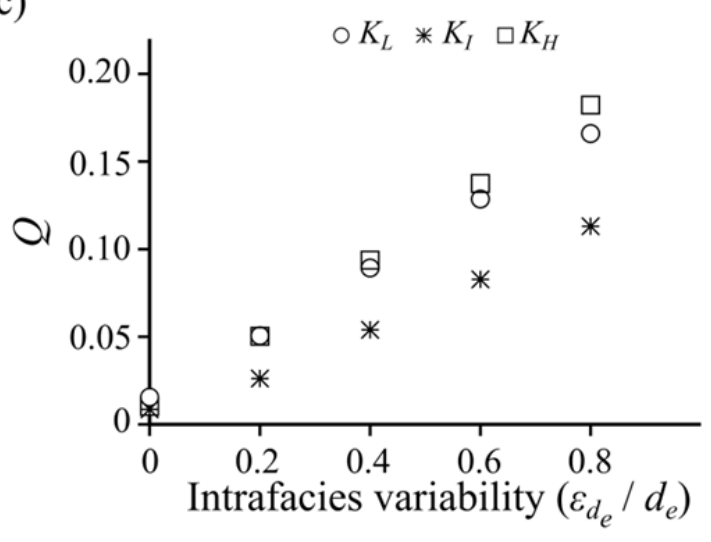

(b)

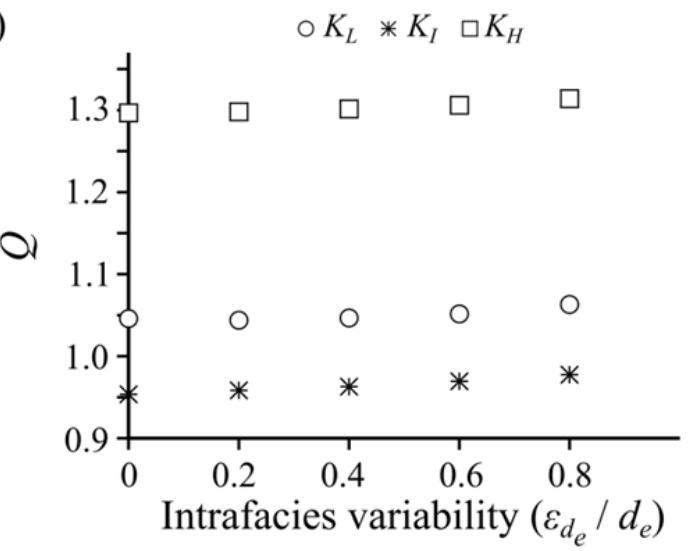

1020 Figure 9. Variation of the accuracy metrics of flowmeter estimates with respect to

1021 intrafacies $K$ variability. (a) $\mathrm{R}^{2}$ values for scenarios considering different $L_{h}$ values. (b) $Q$

1022 values for scenarios considering $L_{h}=2$. (c) $Q$ values for scenarios considering $L_{h}=\infty$.

1023 


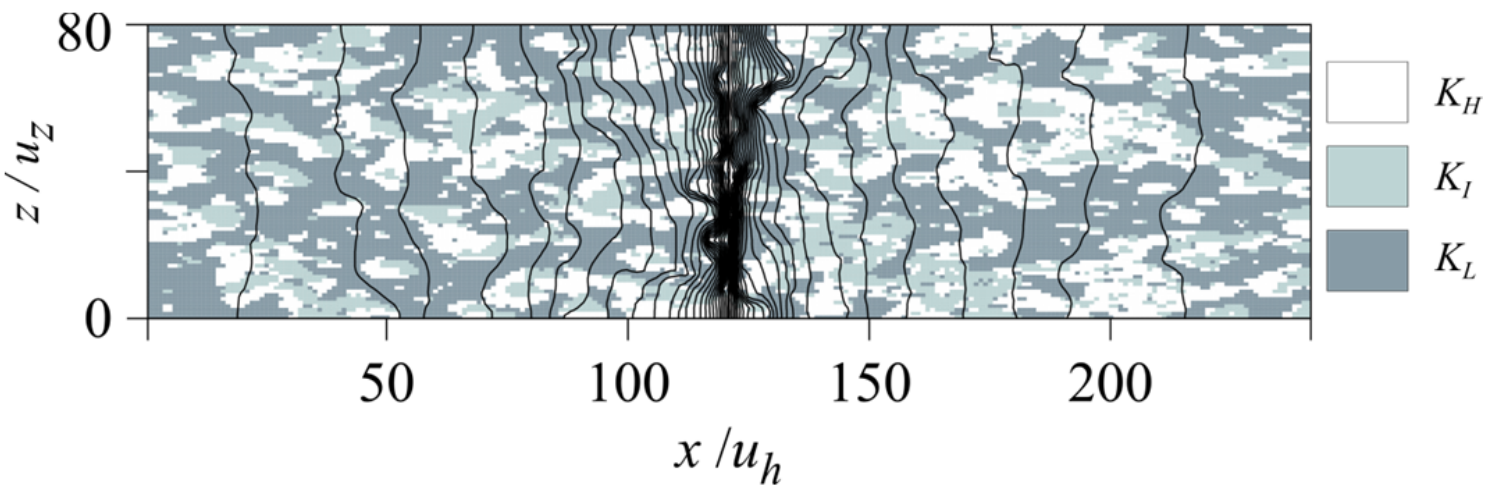

1025 Figure 10. Cross section intersecting the simulated flowmeter test well showing the $K$ 1026 distribution and simulated head contours for (Scenario L_4). 
(a)

1029

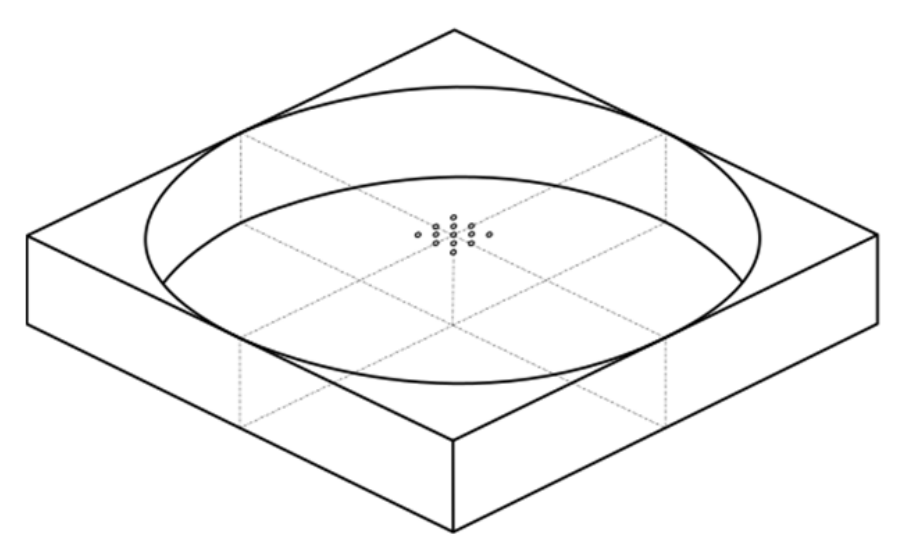

(b)

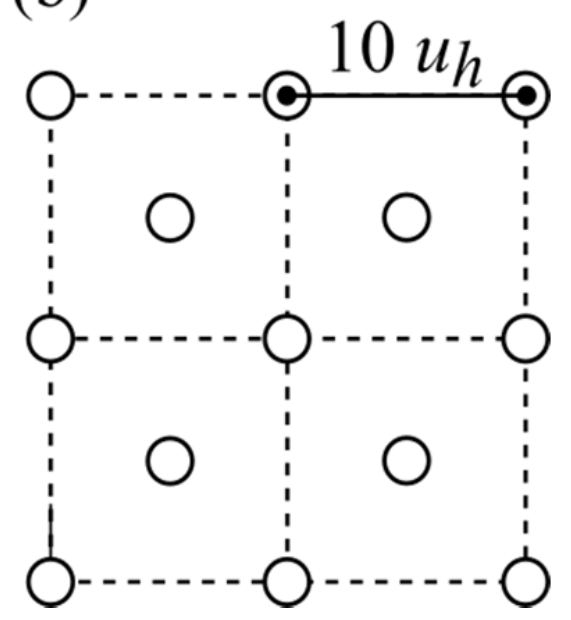

1030

1031 Figure 11. Location of the multiple flowmeter tests simulations.

1032 
(a)

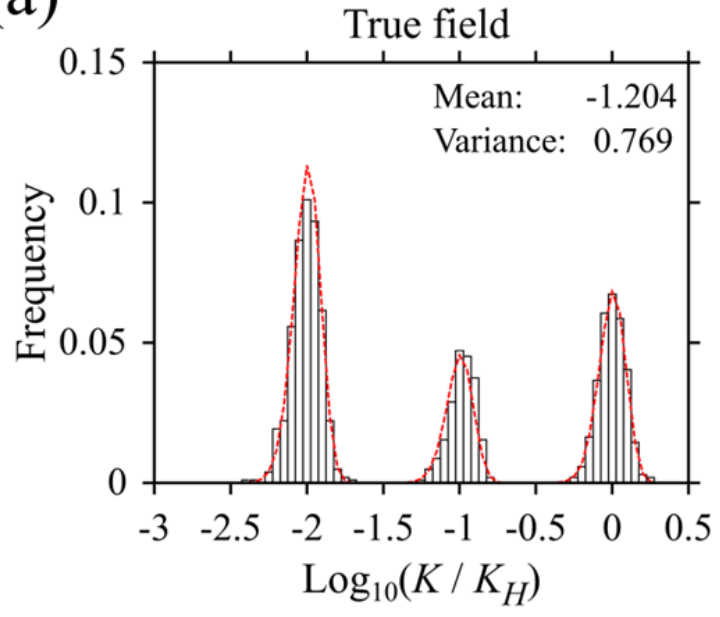

(c)

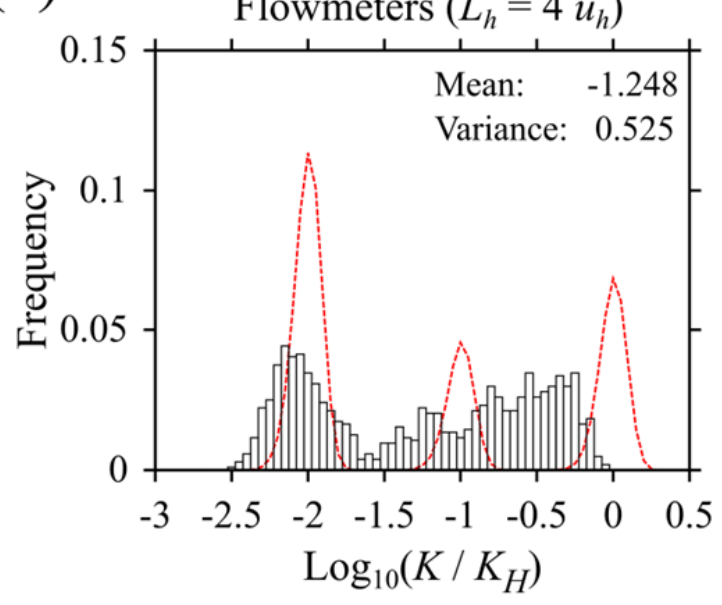

(e)

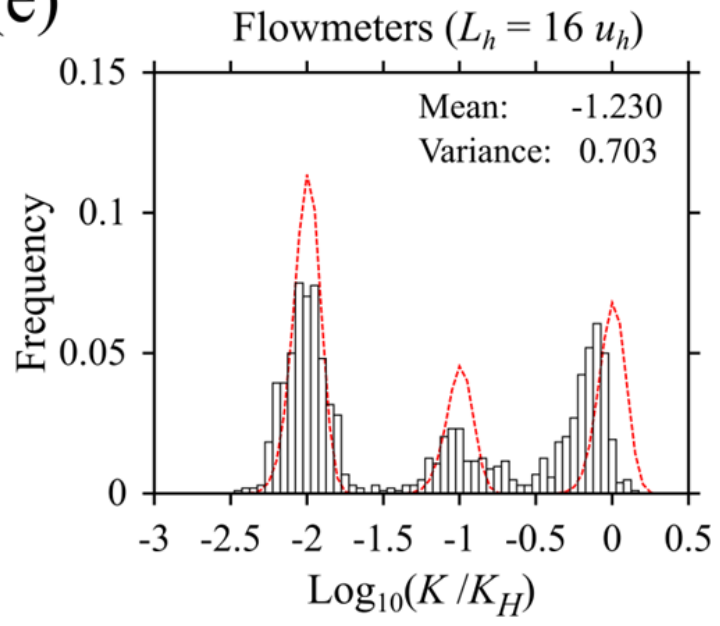

(b) Flowmeters $\left(L_{h}=2 u_{h}\right)$

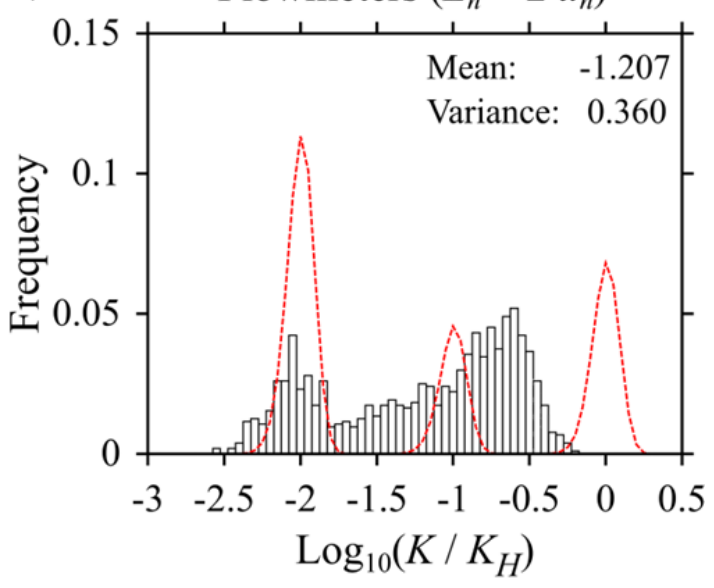

(d)

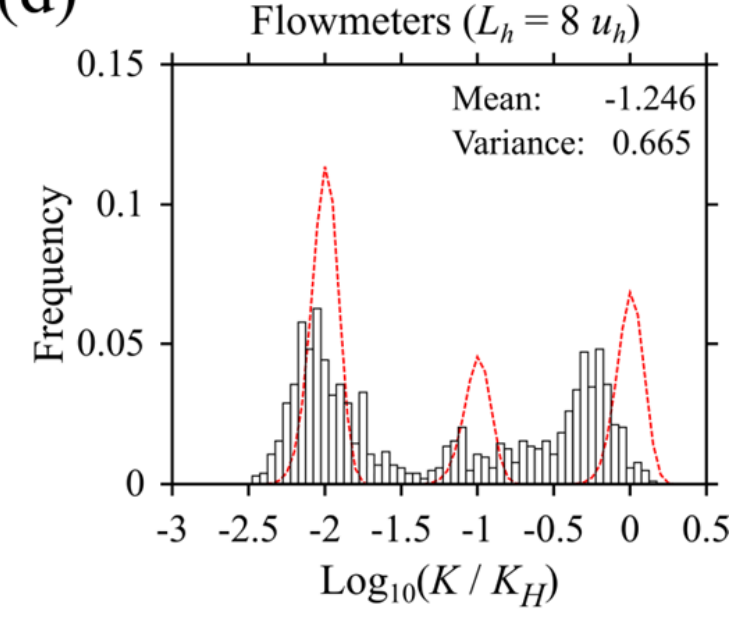

(f)

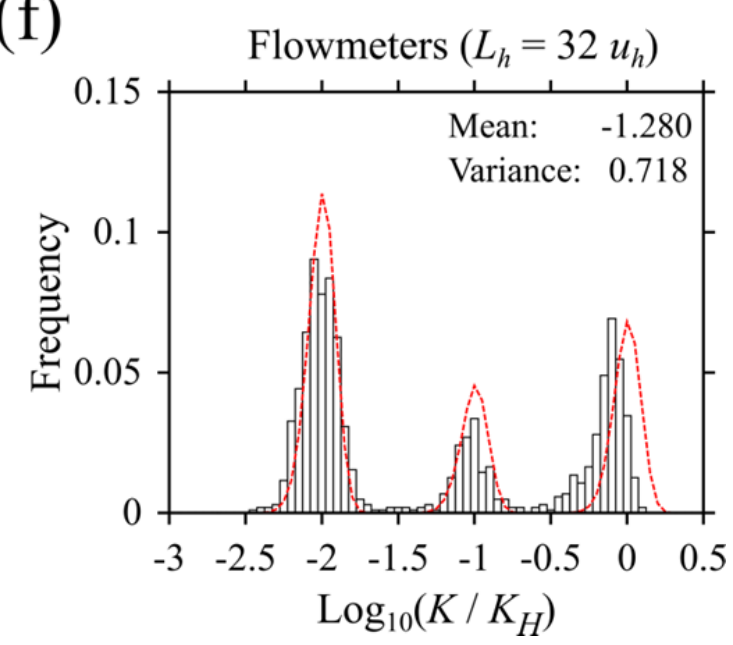

1034 Figure 12. Histograms of the reference and estimated $K$ values for different $K$ field

1035 structures. (a) Reference $K$ values sampled from 13 profiles (white bars) vs. reference 
1036 values in the entire domain (red dashed line). $(\mathrm{b}-\mathrm{f})$. Simulated flowmeter $K$ estimates

1037 from 13 locations (white bars) vs. reference values in the entire domain (red dashed line).

1038 
(a)

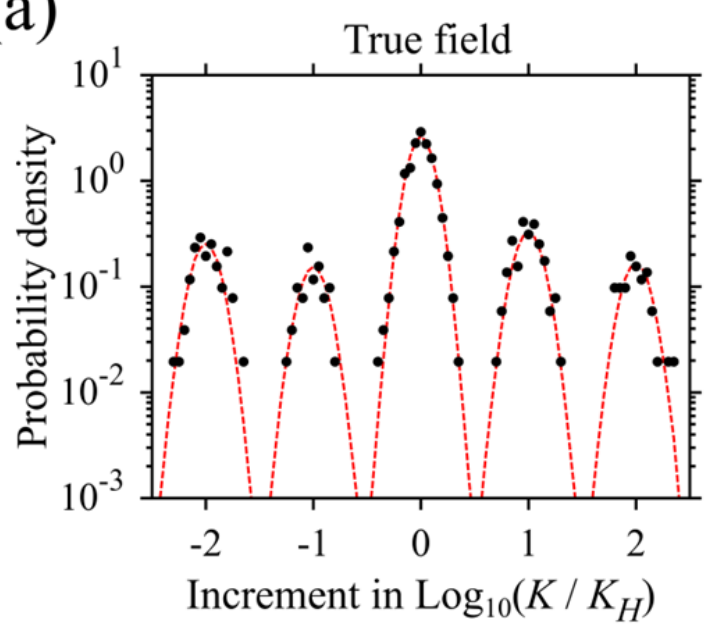

(c)

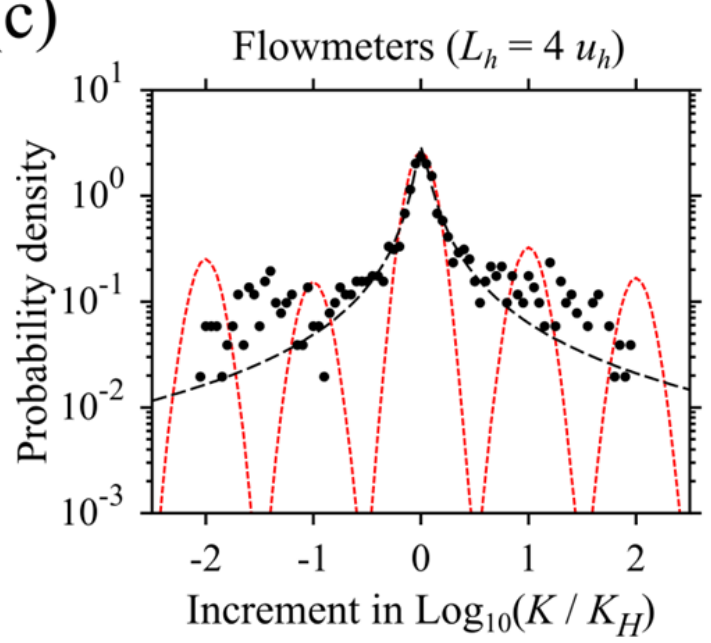

(e)

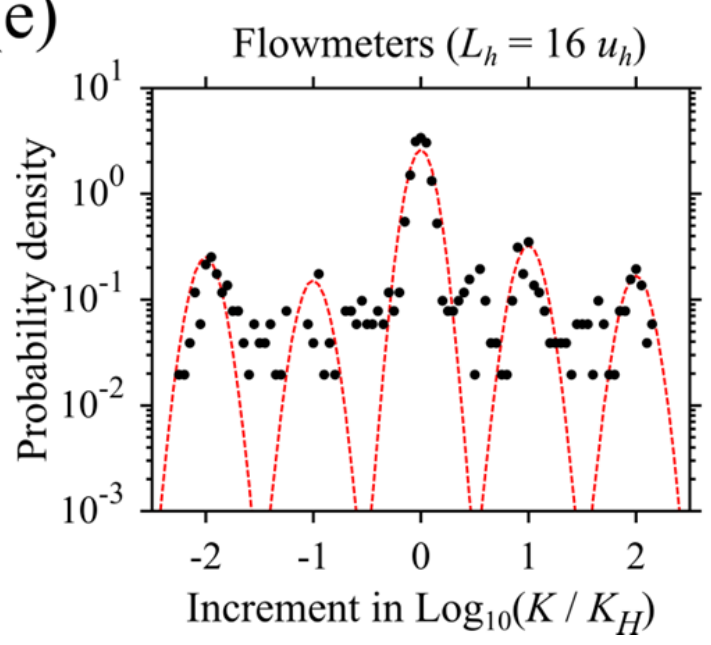

(b)

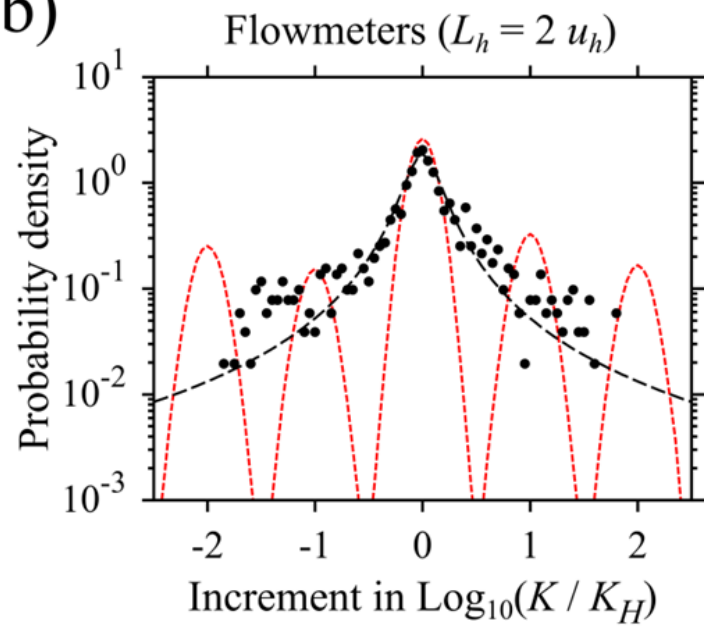

(d)

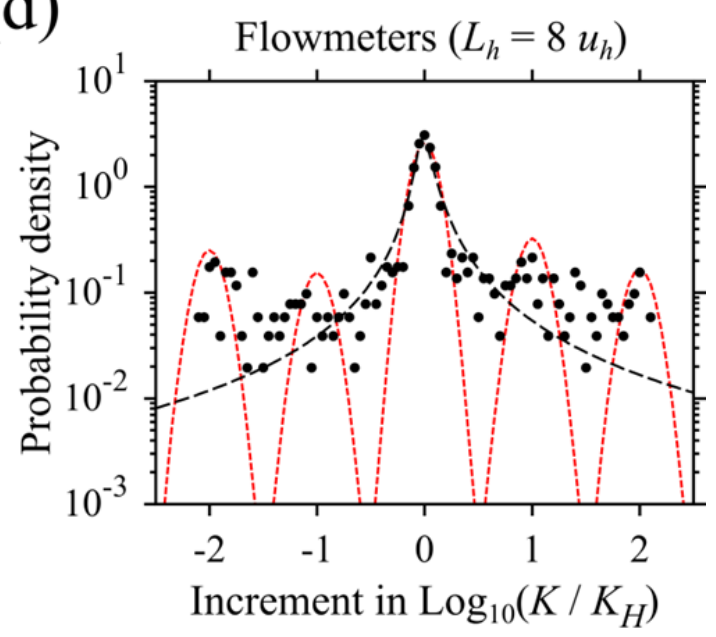

(f)

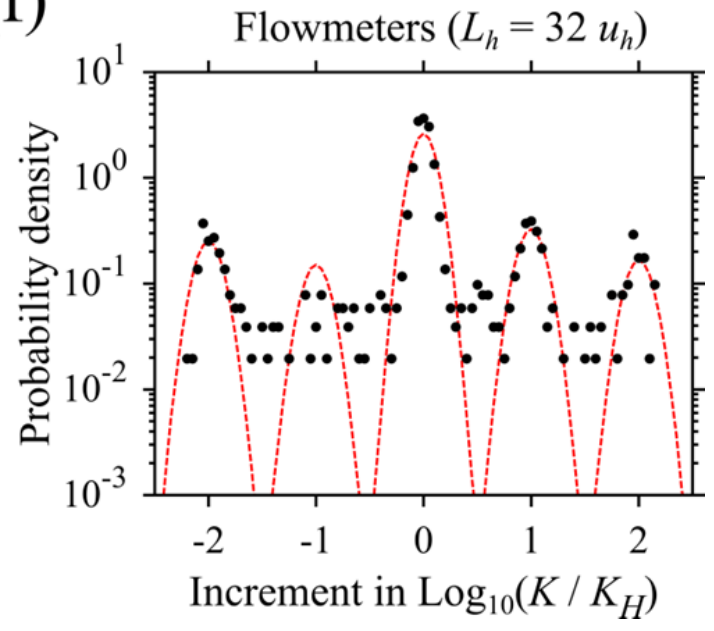

1040 Figure 13. Distribution of the reference and estimated increments in $\log _{10}(K)$. (a)

1041 Increments calculated for reference $K$ values sampled from 13 profiles (black circles) vs.

1042 increments calculated for the entire reference $K$ field (red dashed line). $(b-f)$. Increments 
1043 calculated for flowmeter $K$ estimates from 13 profiles (dots) vs. increments calculated for 1044 the entire reference $K$ field (red dashed line). Black dashed lines in $(b-d)$ indicate best 1045 fitted Levy-stable PDFs. The fitting was performed with an OCTAVE script based on the 1046 method of Koutrouvelis $(1980,1981)$. 